\title{
The Prismatic Surface cell cooling coefficient: a novel cell design optimisation tool \& thermal parameterisation method for a 3D discretised Electro-Thermal Equivalent-Circuit Model
}

Xiao Hua ${ }^{\mathrm{a}}$, Claas Heckel ${ }^{\mathrm{b}}$, Nils Modrow ${ }^{\mathrm{c}}$, Cheng Zhang ${ }^{\mathrm{a}, \mathrm{d}}$, Alastair Hales ${ }^{\mathrm{a}}$, Justin Holloway ${ }^{\mathrm{g}}$, Anmol Jnawali ${ }^{\text {h }}$, Shen $\mathrm{Li}^{\mathrm{a}}$, Yifei Yu ${ }^{\mathrm{g}}$, Melanie Loveridge ${ }^{\mathrm{g}}$, Paul Shearing ${ }^{\mathrm{f}, \mathrm{h}}$, Yatish Patel ${ }^{\mathrm{a}, \mathrm{f}}$, Monica Marinescu ${ }^{\mathrm{a}, \mathrm{f}}$, Liang Tao ${ }^{\mathrm{e}}$, Gregory Offer ${ }^{\mathrm{a}, \mathrm{f}^{*}}$

\footnotetext{
Affiliations:

a. Department of Mechanical Engineering, Imperial College London, SW7 2AZ, United Kingdom

b. Dassault Systèmes Deutschland GmbH, 70563 Stuttgart, Germany

c. Dassault Systèmes AB, SE22363 Lund, Sweden

d. Institute for Future Transport and Cities, Coventry University, CV1 5FB, United Kingdom

e. Envision AESC China Ltd., Shanghai, China

f. The Faraday Institution, Harwell Science and Innovation Campus, Didcot, United Kingdom

g. WMG, The University of Warwick, Coventry, CV4 7AL, United Kingdom

h. The Electrochemical Innovation Lab, Department of Chemical Engineering, University College London, WC1E 6BT, United Kingdom
} 


\begin{abstract}
Thermal management of large format prismatic lithium ion batteries is challenging due to significant heat generation rates, long thermal 'distances' from the core to the surfaces and subsequent thermal gradients across the cell. The cell cooling coefficient (CCC) has been previously introduced to quantify how easy or hard it is to thermally manage a cell. Here we introduce its application to prismatic cells with a $90 \mathrm{Ah}$ prismatic lithium iron phosphate cell with aluminium alloy casing. Further, a parameterised and discretised three-dimensional electro-thermal equivalent circuit model is developed in a commercially available software environment. The model is thermally and electrically validated experimentally against data including drive cycle noisy load and constant current CCC square wave load, with particular attention paid to the thermal boundary conditions. A quantitative study of the trade-off between cell energy density and surface $\mathrm{CCC}$, and into casing material selection has been conducted here. The CCC enables comparison between cells, and the model enables a cell manufacturer to optimise the cell design and a systems developer to optimise the pack design. We recommend this is operated together holistically. This paper offers a cost-effective, timeefficient, convenient and quantitative way to achieve better and safer battery designs for multiple applications.
\end{abstract}




\section{Introduction}

Global sustainable development requires rapid and widespread changes across all parts of the energy system[1]. The inevitable electrification of transport is an essential solution to reduce greenhouse gases emitted by burning fossil fuels in internal combustion engines[2,3]. In order to enable this, lithium ion batteries (LIBs) need to be cheaper, safer and last longer[4,5]. The thermal management system (TMS) is a critical sub-system of an electric vehicle (EV) design. Firstly, if a LIB generates more heat than can be dissipated this can lead to thermal runaway[6,7]. Secondly, large temperature deviations can cause accelerated degradation and/or require de-rating of performance[8-10]. A TMS clearly cannot be avoided. However, thermal management will cause a thermal gradient across a LIB due to the finite and anisotropic thermal conductivity[5]. This combined with the strong temperature dependence on the impedance means different layers/regions will have different values of impedance. As a consequence, current inhomogeneities are caused which exacerbate the thermal gradients in a positive feedback mechanism[11]. Such thermal inhomogeneities caused by different thermal management methods (e.g. surface cooling or tab cooling) can be a significant contributor towards accelerated LIB degradation[4,12].

TMSs broadly fall into two categories, convective air cooling and conductive liquid cooling. Nowadays, air cooling is restricted to low discharge rate applications, as high volumetric heat generation limits the usage of air-cooling[13-15]. Cooling can also be applied to different cell thermal interfaces, such as tabs, side surfaces or bottom surfaces. With the current generation of cell designs, surface cooling is typically the only feasible cooling method for most automotive applications, due to the high heat rejection rates achievable[16-19]. For simplicity, the majority of the TMS designs cool only one side of the cell, in order to achieve higher pack level performance[20,21]. Evaporative and two-phase cooling systems fall into a different category.To understand and study the importance of TMS design on LIB performance, models are required. A robust LIB model should be able to capture both the voltage and thermal response of the battery. Multi-node 2D/3D electro-thermal coupled equivalent circuit models (ECM) are often chosen owing to their capability of predicting the internal current and thermal inhomogeneities within LIBs[4,22]. They are easier to 
implement and easier to parameterise compared to physics based models, and require less computational power to scale from a lumped cell model to a multi-dimensional model [4] as pioneered by Newman, Tiedemann et al and others[23-25]. Parameterisation is critical for high accuracy and can be achieved through simple pulse discharging (PD)[26-28]. Two reviews of ECM models are recommended for further reading[29,30]. Previous work by some of the authors used an ECM model as a design tool, which showed that increasing cell tab width and thickness and changing tab position could significantly improve the performance of a LIB pouch cell[31].

In the same way that volumetric energy density is defined by a single metric, Wh. $\mathrm{L}^{-1}$, when designing a cell, it is useful to have a single comparable metric to compare how easy it is to thermally manage a cell.

The Cell Cooling Coefficient (CCC), with units of W.K ${ }^{-1}$ was introduced by Hales et al. [5] in response to this need. It describes the rate of heat transfer that will occur due to the thermal gradient from the hottest point of a cell and its cooled surface, whilst it is generating heat throughout its volume. The CCC is a new cell evaluation standard for quantifying the rate of heat rejection[5,12]. A cell will have a unique $\mathrm{CCC}$ for each surface that can be managed, and each can be measured empirically without any knowledge of the cell internal structure. The CCC allows the comparison of different cell formats, geometries, sizes and chemistries experimentally, just like volumetric or specific energy density can be compared. Cell tab and cell surface cooling for pouch cells have been previously defined[5,15].

From a design point of view, the CCC describes the theoretical maximum performance for a given surface. For example, if a given rate of heat transfer can be achieved then the maximum internal temperature inside the cell can be predicted. Similarly if a maximum internal temperature is required, then the rate of heat transfer required for different surface temperatures can be calculated. How/if the calculated rate of heat transfer is achievable is then very much dependent upon how that surface is cooled. The surfaces can be cooled by blowing air over them (convective air cooling) or by flowing liquid over them (conductive liquid cooling), or by flowing liquid through a cooling plate in contact with the surface of the cell (also conductive liquid cooling). In all cases the thermal gradients outside the cell must be taken into consideration, as the CCC only considers the temperature at the surface of the 
cell without taking into account any thermal interface resistance or losses elsewhere in the cooling system. In this way the CCC is a property of the cell itself and is independent of the way that the cell is thermally managed.

In this study, a large format prismatic Lithium iron phosphate (LFP) battery is examined. The prismatic form factor is favoured by some EV manufacturers due to its ease of manufacturing using a jellyroll design, and robust packing assembly because of its metallic hard casing[32]. This study describes how to measure the CCC for a prismatic cell for the first time. The measured values are then compared to a discretised thermally coupled ECM. The threedimensional discretised thermally coupled ECM is developed using 'Dymola' software in collaboration with Dassault Systèmes. The CCC experimental data provide a novel validation method in addition to the generic independent validation against experimental drive cycles. The ECM is then used as a design tool to explore how changes to the cell design affect the CCC. Various cell design choices including changing the casing materials (e.g. pure aluminium, aluminium alloy, steel and aluminium laminated film), and cell physical geometries (e.g. thickness) are evaluated. Such analysis enables a quantifiable way of studying the trade-offs between the volumetric energy density and specific energy with the CCC surface $\left(C C C_{\text {surf }}\right)$ values and therefore the degree of difficulty implementing a TMS.

\section{Model Development}

\subsection{Overview}

A three-dimensional $(\mathrm{x}, \mathrm{y}, \mathrm{z})$ discretised electro-thermal ECM model is developed and implemented, which enables the simulation of cell internal states in all directions, including temperature distribution, current density and voltage response. A network of electric and thermal models represents the simulated battery, where the electric and thermal networks are exchanging the temperature and heat generated in each of the discretised volumes. The model is developed and implemented in Dymola [33] (Dynamic Modelling Laboratory), a tool for modelling and simulation of complex multi-domain systems. Dymola uses the objectoriented, acausal and component-oriented modelling language, termed Modelica.[34,35] The Battery Library, a Modelica based library for the design of battery systems, builds the base 
for the development and implementation, while both Dymola and the Battery Library are commercial tools from Dassault Systèmes.

\subsection{Electric Model - Equivalent circuit model}

As shown in Fig.1, the electric model is a network of parallel-connected ECMs, where each ECM consists of a voltage source, representing the open-circuit voltage (OCV) $U_{\text {oc }}$, a serial resistor $R$ and two R-C branches connected in series. The resistors are described by Ohm's law in Eqn.(1), the capacitors are described by Eqn.(2) and the cell terminal voltage is given by Eqn.(3):

$$
\begin{gathered}
U_{i}=R_{i} \cdot I_{i} \\
I_{i}=C_{i}(t) \cdot \frac{d U_{i}}{d t} \\
U_{E C M}=U_{\mathrm{oc}}-\sum_{j=1}^{2} U_{R C}-I R
\end{gathered}
$$

Where $U_{E C M}$ is the cell terminal votlage, $I$ is the applied current and $U_{R C}$ is the voltage loss at each R-C branch. $U_{i}, R_{i}, I_{i}$ and $C_{i}$ is the voltage, resistance, current and capacitance values for each individual component $i$ respectively within the ECM networks. 

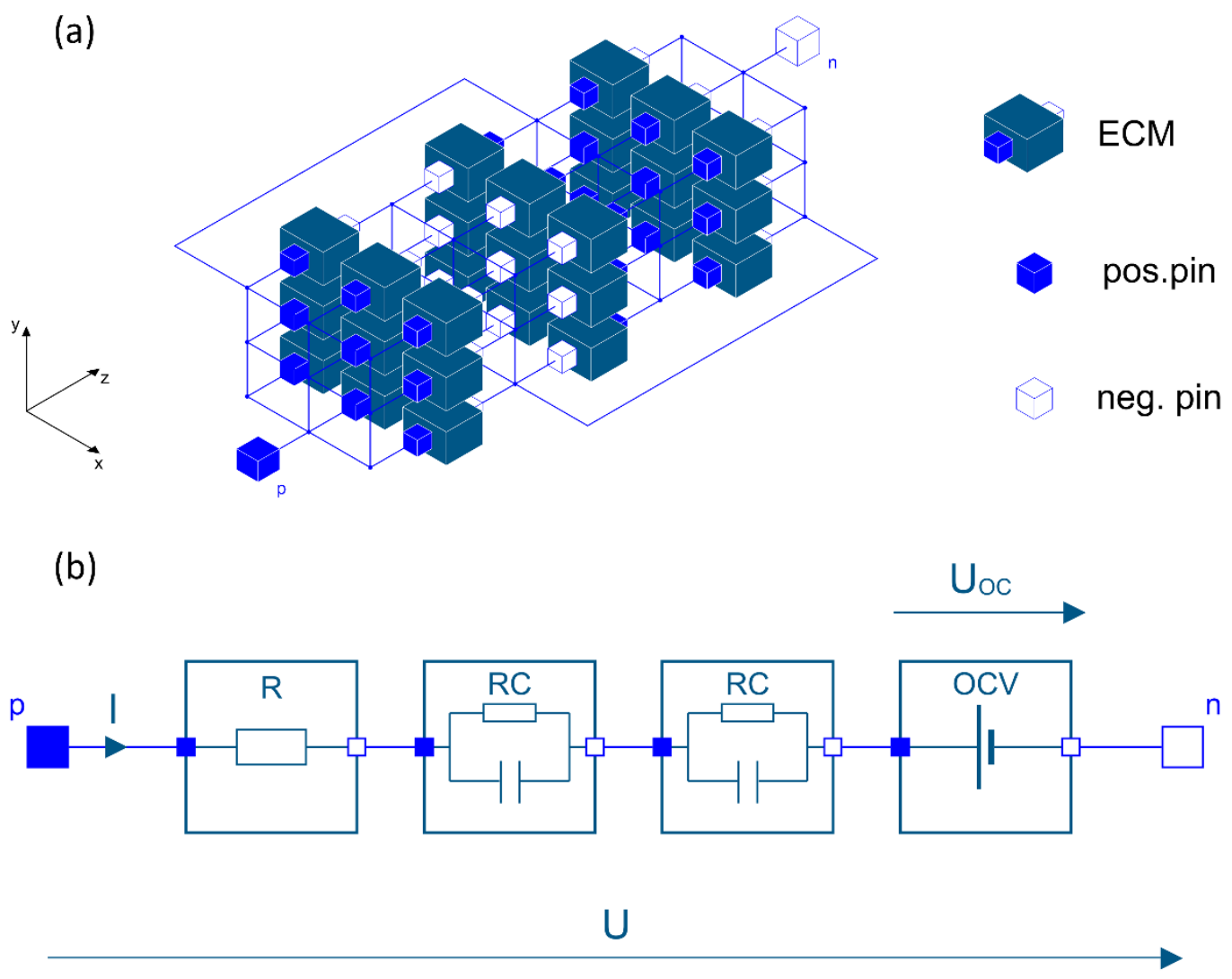

Fig. 1: (a)Electrical Model demonstration, in three dimensions, (x, y, z), (b)Battery equivalent circuit model with $2 R-C$ branches.

All components of the ECM use lookup tables with State of Charge (SoC) and temperature $T$ as inputs. The SoC is calculated from the ECM current $I_{E C M}$ and the nominal capacity $C_{\text {nom }}$ of the ECM:

$$
\operatorname{SoC}=\operatorname{SoC}(t=0)+\frac{1}{C_{\text {nom }}} \int I_{E C M} d t
$$

The total heat flow generated by each ECM $\dot{Q}_{\text {loss }}$ is contributed from the reversible heat generation $\dot{Q}_{\text {rev }}$ and irreversible heat generation $\dot{Q}_{\text {irr }}$ :

$$
\dot{Q}_{\text {loss }}=\dot{Q}_{\mathrm{irr}}+\dot{Q}_{\mathrm{rev}}
$$

The irreversible heat is calculated from the open circuit voltage $U_{O C}$ and the current $I_{E C M}$ and the voltage $U_{E C M}$ of each ECM element, while the reversible heat is calculated from the derivative of the open circuit voltage with respect to the temperature. The SoC dependent derivative is adopted from [32] where it was measured on a similar chemistry. This reversible heat is caused by the entropy changes in electrodes at different SoC, where the CCC 
validation only generate heat at a single SoC point. The entropic heat generation cancel each other when the input current is a switching square wave, therefore the value from literature [32] is taken to simplify the development procedure. The sum of the irreversible and reversible heat leads to the total heat flow generated by each ECM as described by Eqn. (6)(8):

$$
\begin{gathered}
\dot{Q}_{\mathrm{irr}}=\left(U_{E C M}-U_{O C}\right) \cdot I_{E C M} \\
\dot{Q}_{\mathrm{rev}}=I_{E C M} \cdot T \cdot \frac{\partial U_{O C}}{\partial T} \\
\dot{Q}_{\text {loss }}=\left(U_{E C M}-U_{O C}\right) \cdot I_{E C M}+I_{E C M} \cdot T \cdot \frac{\partial U_{O C}}{\partial T}
\end{gathered}
$$

The electrical properties are assumed to be homogenous throughout the entire cell. This allows scaling of the resistances and capacitances from cell level to each ECM for the nth ECMs by:

$$
\begin{gathered}
R_{E C M}=n \cdot R_{\text {cell }} \\
C_{E C M}=\frac{C_{\text {cell }}}{n}
\end{gathered}
$$

where $R_{E C M}, C_{E C M}, R_{\text {cell }}$ and $C_{\text {cell }}$ are the ECM resistance \& capacitance and unit cell resistance and capacitance respectively.

\subsection{Thermal Model}

As shown in Fig.2(a), the thermal network consists of several thermal elements. The subcomponents of the cell model, as there are the jelly roll and the casing walls for all six sides, are composed of these cuboid elements. The number of elements in $\mathrm{x}, \mathrm{y}$ and $\mathrm{z}$ direction can be determined by setting the corresponding model parameters. The edge lengths of the elements are uniformly adjusted according to the overall length of the cell dimensions and to the selected degree of discretisation.

The basic thermal elements are modelled according to the finite volume method (FVM). Their heat capacity $C$ is assumed to be concentrated in the centre. It is calculated according to:

$$
C=V \cdot \rho \cdot c_{p}
$$

where $V$ is the volume of the element, $\rho$ is the density of the element and $c_{p}$ is the 
specific heat capacity of the element.

The material properties are assumed to be constant over temperature as the temperature range in which the model used is relatively small. In the thermal base element, the heat $\dot{Q}_{c o n d}$ is conducted in all three dimensions in the form of 1D heat conduction between its centre and the according side faces (essentially six directions for a cuboid element):

$$
\dot{Q}_{\text {cond }}=k \cdot \frac{A}{x} \cdot \Delta T
$$

where $k$ is the thermal conductivity of the element, $A$ is the cross-sectional area of the element, $x$ is the distance of the heat conduction range of the element and $\Delta T$ is the temperature difference at both end during the heat conduction of the element. Therefore, the heat balance of the basic thermal element is described by Eqn. (13) and Eqn. (14):

$$
\begin{gathered}
C_{c c, i} \frac{\partial T}{\partial t}=\sum_{i=1}^{6} \dot{Q}_{\text {cond_cC,i }} \\
\rho_{i} c_{p, i} \frac{\partial T}{\partial t}=\sum_{i=1}^{6} k_{i} A \frac{\partial T}{\partial x}
\end{gathered}
$$

where $C_{c c, i}$ is the heat capacity of current collector elements, $\dot{Q}_{c o n d \_c C, i}$ is the heat conduction rate of current collector element in the $i$ direction.

As shown in Fig.2(a), the jellyroll consists of layers of positive \& negative current collectors and electrochemical elements that are alternately connected to each other in the z-direction. The number of layers of electrochemical elements in the z-direction equals to the desired discretisation in the z-direction $\left(n_{z}\right)$. Since the first and the last layer of the jellyroll model are pure current collector layers, there are $n_{z}+1$ current collector layers. 
(a)

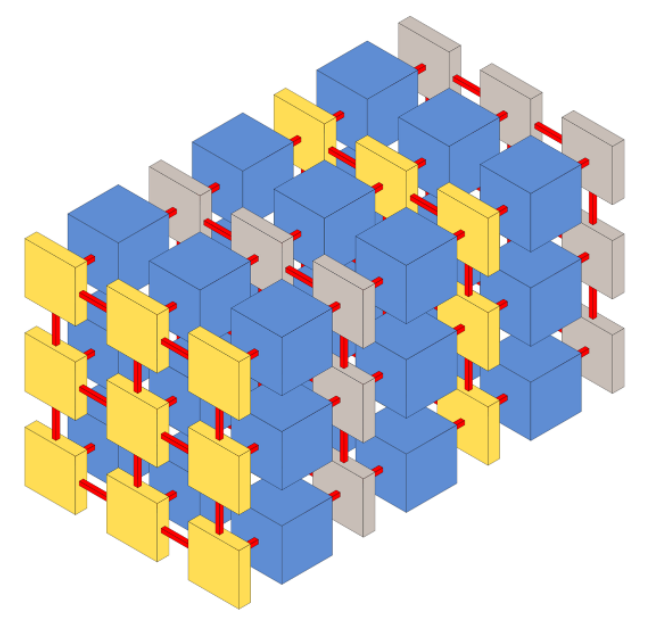

neg. current collector

pos. current collector

electrochemical cell

thermal connection

(b)
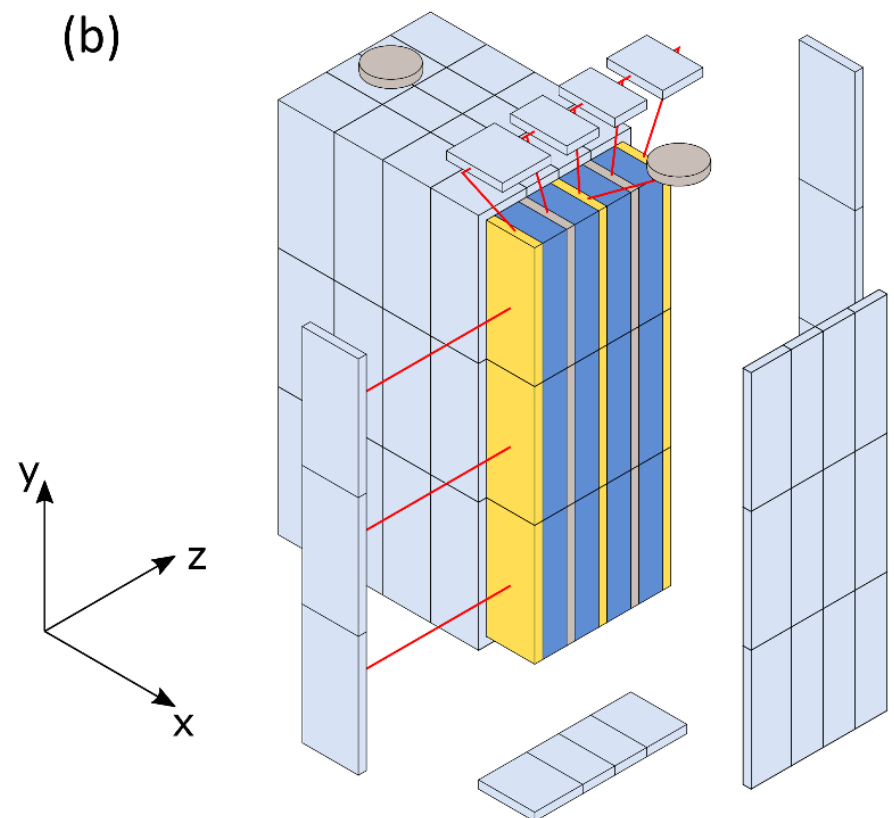

casing

neg. current collector

pos. current collector

electrochemical cell

pin

$\checkmark$ thermal connection

Fig.2: (a) Thermal Model demonstration of electrode stack, in three dimensions, (x, $y, z)$, (b)

Cell level Thermal Model schematic, in three dimensions, $(x, y, z)$.

The electrochemical cell element consists of the anode, the cathode and the separator. The electrode stack is assumed as a single homogeneous mixture of materials. An assumption is made in the thermal connection here: as the thermal conductivity of the electrochemical cell elements are relatively small in comparison to the current collectors, the heat conduction inplane for the electrochemical cell elements is assumed to have negligible influence on the thermal behaviours and is therefore ignored. [36]

Therefore, besides from Eqn. (13) and (14), another thermal balance equation is implemented in the thermal network, where the heat is only conducted between the electrochemical cell 
elements and current collector elements. This simplification reduces the total number of the heat transfer equations to be solved, and therefore, an optimised simulation performance with less required computational force is achieved. The corresponding heat balance equations are described as in Eqn. (15) and (16):

$$
\begin{gathered}
C_{c e l l, i} \frac{\partial T}{\partial t}=\sum_{i=1}^{2} \dot{Q}_{\text {cond_cell,i}}+\dot{Q}_{\text {loss }} \\
\rho_{i} c_{p, i} \frac{\partial T}{\partial t}=\sum_{i=1}^{2} k_{i} A \frac{\partial T}{\partial x}+\dot{Q}_{\text {loss }}
\end{gathered}
$$

where the $\dot{Q}_{\text {loss }}$ is the heat generated by the electrical model, therefore coupling the electrical model network with the thermal model network. $C_{c e l l, i}$ is the heat capacity of electrochemical cell elements, $\dot{Q}_{\text {cond_cell,i }}$ is the heat conduction rate of current collector element in the $i$ direction.

The heat balance has an additional heat flow rate $\dot{Q}_{\text {loss }}$ added because every electrochemical cell element has an associated ECM element in the electrical model. Information is exchanged between these pairs of elements. The ECM element calculates the amount of heat generated in the corresponding part of the cell and this information is passed on to the thermal element. The temperature of the thermal element, in turn, is passed to the ECM and interacts with the calculation of the internal resistance and thus the heat generation. In Fig.2 (b), the electrochemical cell elements of the jellyroll are only in thermal contact with the current collectors, where they are not directly connected to the casing. The casing elements are connected to the current collectors, respectively. Like the actual cell, the pins have a cylindrical shape, where the heat conduction is modelled through FVM in the ydirection. The welding region is modelled here, as a connection between the pins and the current collectors, where the welding electrical counterpart is used to calculate the heat generation of the welding. The ohmic resistance of the welding regions are considered constant, which is independent of the operating temperatures. The pins are located at the same end of the cell and are not directly connected to the casing as there is electrical insulation and therefore thermal insulation between the pins and the casing. The welding regions are connected to the inner half of the corresponding current collectors, like the actual 
cell configuration.

As listed in Table 1 and Table 2, the thermal conductivities and the heat capacities of the current collectors, the casing material and the pin models are calculated based on the geometric measurements of the thermal elements, and material properties from literature[4,5,12,15,31,37,38]. The thermal conductivity and the specific heat capacity of the electrochemical elements, on the other hand, have been determined using parameter fitting, where the test bench has been rebuilt in Dymola, which is described in section 3.2. The fitted thermal parameters are based on the original electrode stack parameters from literature $[4,38]$, where Kim et al. and Zhao et al. considered the positive/negative electrode material and the separator independently. Here, the electrode stack has been considered as a single thermal element in each discretised thermal element, therefore a fitting algorithm is necessary to validate the parameter. The fitted thermal conductivity and heat capacity of electrode stack are close to the values in the literature, with same order of magnitude. The measured current, voltage and temperature signals, including the ambient temperature signal, are imported into the model. The current and the ambient temperature signals are used as boundary conditions during the simulation, while the measured cell surface and pin temperatures are used for comparison with the corresponding signals of the cell model and thus to calculate the optimisation objective. This model, converted to a Functional Mock-up Unit (FMU) [39], is used in a Python script to determine the optimal material values of the electrochemical cell elements. To run the FMU the python package FMPy [40] is used. For the parameter optimisation, the differential evolution algorithm from the package scipy.optimize is used[41]. It is assumed that the fitted material data take into account the cell-internal heat transfer resistances and therefore do not need to be considered separately. 
Table 1: Material properties used in the thermal model.

\begin{tabular}{|c|c|c|c|c|}
\hline Material & $\begin{array}{c}\text { Thermal } \\
\text { conductivity } \\
{[\mathrm{W} /(\mathrm{mK})]}\end{array}$ & $\begin{array}{l}\text { Density } \\
{\left[\mathrm{kg} / \mathrm{m}^{3}\right]}\end{array}$ & $\begin{array}{c}\text { Specific heat } \\
\text { capacity } \\
{[\mathrm{J} /(\mathrm{kgK})]}\end{array}$ & Comment \\
\hline $\begin{array}{l}\text { Aluminium, } \\
\text { pure }\end{array}$ & $180[12]$ & 2700 [37] & $910[37]$ & $\begin{array}{l}\text { From }[12,37], \text { used for } \\
\text { current collectors }\end{array}$ \\
\hline $\begin{array}{l}\text { Aluminium, } \\
\text { Alloy }\end{array}$ & 77 & 2700 & 910 & Fitted, used for casing \\
\hline Copper & $398[4,12]$ & $8960[31,37]$ & $385[31,37]$ & $\begin{array}{c}\text { From }[4,12,31,37], \text { used for } \\
\text { current collectors }\end{array}$ \\
\hline $\begin{array}{c}\text { Brass } \\
(\mathrm{CA} 121)\end{array}$ & $123[5,15]$ & $8470[5,15]$ & $380[5,15]$ & $\begin{array}{c}\text { From }[5,15], \text { used for } \\
\text { busbars }\end{array}$ \\
\hline $\begin{array}{l}\text { Jellyroll } \\
\text { (Anode + }\end{array}$ & $0.164[4]$ & $1900[38]$ & $693[38]$ & $\begin{array}{l}\text { Density: datasheet from cell } \\
\text { manufacturer }\end{array}$ \\
\hline $\begin{array}{l}\text { Separator + } \\
\text { Cathode) }\end{array}$ & & & & $\begin{array}{l}\text { Thermal Conductivity and } \\
\text { spec. heat capacity: fitted } \\
\text { based on }[4,38], \text { used for } \\
\text { electrochemical cell }\end{array}$ \\
\hline
\end{tabular}

Table 2: Cell component dimensions, measured from cell dismantling experiment.

\begin{tabular}{lll}
\hline Component & Thickness (of one layer) [mm] & Comment \\
\hline Neg. current collector & 0.0154 & Number of layers $=52$ \\
Pos. current collector & 0.0195 & Number of layers $=52$ \\
JR layer (Anode, & 0.3216 & Number of layers $=103$ \\
Separator, Cathode) & & \\
Casing & 0.779 & \\
Neg. welding & $26 * 0.0154$ & \\
Pos. Welding & $26 * 0.0195$ & \\
\hline
\end{tabular}

\section{Experimental}

\subsection{ECM parameterization experiments}

Several pulse discharge parameterization experiments under various ambient temperatures $\left(10^{\circ} \mathrm{C}, 20^{\circ} \mathrm{C}, 30^{\circ} \mathrm{C}\right.$ and $\left.40^{\circ} \mathrm{C}\right)$ have been carried out on the cell. Before parameterization experiments were carried out, the cell underwent five charge/discharge cycles for reconditioning and demonstrated stabilised capacity. The cell is charged using the same constant current constant voltage $(\mathrm{CC}-\mathrm{CV})$ test procedure to make sure the initial $\mathrm{SoC}$ of the battery is consistent for all the parameterization tests. The CC current is $1 \mathrm{C}(90 \mathrm{~A})$ and the CV 
voltage is $3.65 \mathrm{~V}$. The cut-off charging current of the $\mathrm{CV}$ procedure is $\mathrm{C} / 50(1.8 \mathrm{~A})$. The cutoff voltage during discharge procedure is $2.5 \mathrm{~V}$.

The cell was evenly wrapped with nitrile rubber insulation material (RS Pro, thickness 25 $\mathrm{mm}$, thermal conductivity $0.034 \mathrm{~W} / \mathrm{mK}$ ) across the entire cell surface, as shown in the Fig.3. The cell was placed in the centre of the bottom shelf of a thermal chamber (Binder, model KB23). K-type thermocouples (TC) were placed and taped with Kapton ${ }^{\circledR}$ polyimide films tape on the centre of the prismatic aluminium shell surface $(200.5 \times 130.3 \mathrm{~mm})$ to measure surface temperature, and on the cell positive and negative pins to measure the cell pin temperatures (TC_C1-C5 \& TC_P1-P2). The thermal boundary condition has been designed in this format to approach a near 'adiabatic condition' by minimizing convection in the thermal chamber, this is done to minimize the internal thermal gradient of the cell being tested and to avoid the problems this can cause, as described by Zhao et al[4]. A single channel battery cycling system (BioLogic, HCP-1005) was used for charging/discharging the cell.

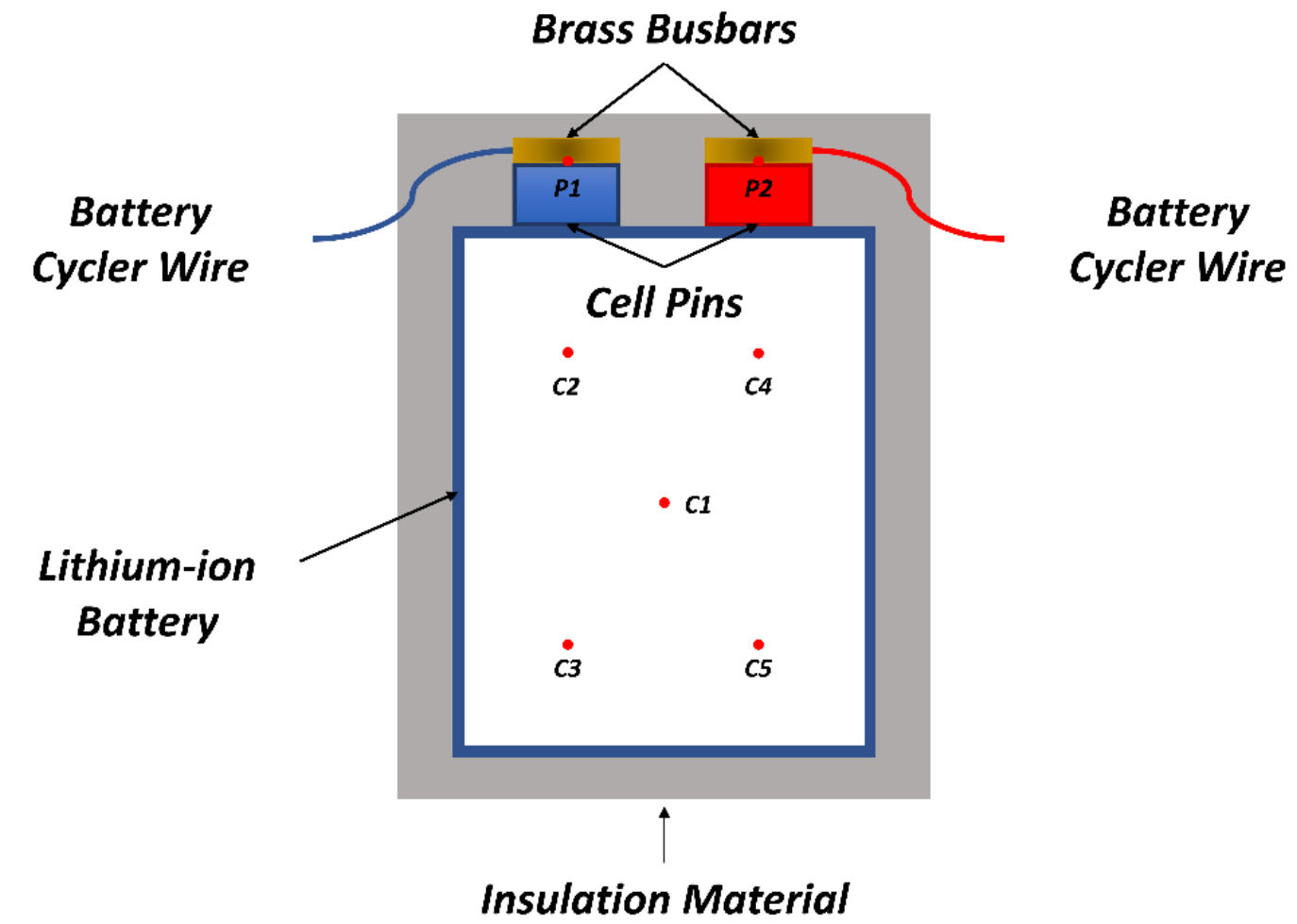

Fig.3: Parameterization experiments and Drive cycle experiment testing rig demonstration. The pulse discharge tests were carried out to generate data for the ECM parameter identification in this work. The test involves repetitions of a constant current discharge pulse 
at $1 \mathrm{C}(90 \mathrm{~A})$ followed by a resting period of 2 hours. This process starts from $100 \% \mathrm{SoC}$ and finishes till the voltage reaches $2.5 \mathrm{~V}$. The SoC step length is $1 \%(9 \mathrm{Ah})$ for $0 \%-10 \%, 90 \%-$ $100 \% \mathrm{SoC}$, and $5 \%(4.5 \mathrm{Ah})$ for $10 \%-90 \%$. The current input and the corresponding voltage response are shown in Fig.4.

The model training results are given in Fig.4, where the Root-Mean-Square Error (RMSE) of the model's voltage prediction underload at $20{ }^{\circ} \mathrm{C}$ using the pulse discharge data from $100 \%$ SoC to $2 \%$ SoC is $4.9 \mathrm{mV}$. The large error spikes in Fig.4(d) come from the relaxation period which does not affect the calculation of the battery internal heat generation. The $10{ }^{\circ} \mathrm{C}, 30{ }^{\circ} \mathrm{C}$ and $40{ }^{\circ} \mathrm{C}$ experimental data, model training results, the detailed parameter identification procedure, a detailed data analysis and mathematical equations are given in the supplementary material A.
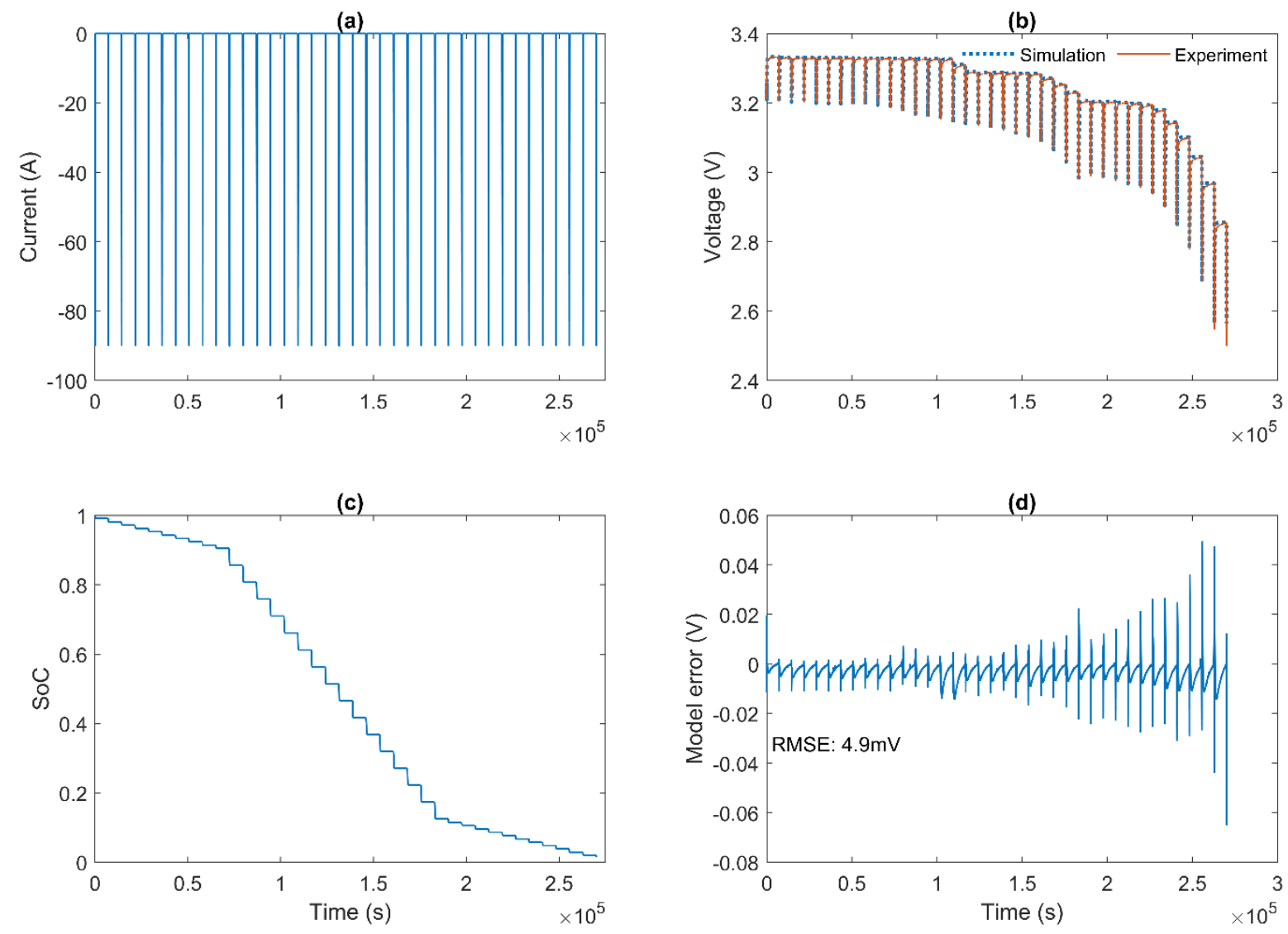

Fig.4: Simulation result for the pulse discharge experiment: (a)Input Current (b)Cell Terminal Voltage: Comparison of the simulation and the experimental data using the $1 \%$ \& $5 \%$ SoC pulse discharge data at $1 \mathrm{C}(90 \mathrm{~A})$ with a 120 minutes relaxation period at $20{ }^{\circ} \mathrm{C}$ (c)State of Charge (SOC),(d) corresponding modelling error, shows a RMSE of $4.9 \mathrm{mV}$. 


\subsection{Adiabatic condition validation experiment: Drive cycle}

On the same testing rig, as shown in Fig.3., the model and the parameters (both electrical and thermal parameters) are validated against a bespoke noisy load based on the US06 drive cycle current profile but with an enlarged average current value and extended test time. The Fig.6 in section 4 demonstrates the current profile examined, the measured and simulated voltage and cell surface temperature responses, respectively. The cell was pre-charged to $100 \%$ SoC, with a $1 \mathrm{C}(90 \mathrm{~A}) \mathrm{CC}-\mathrm{CV}$ charge.

\subsection{Cell cooling coefficient experiments}
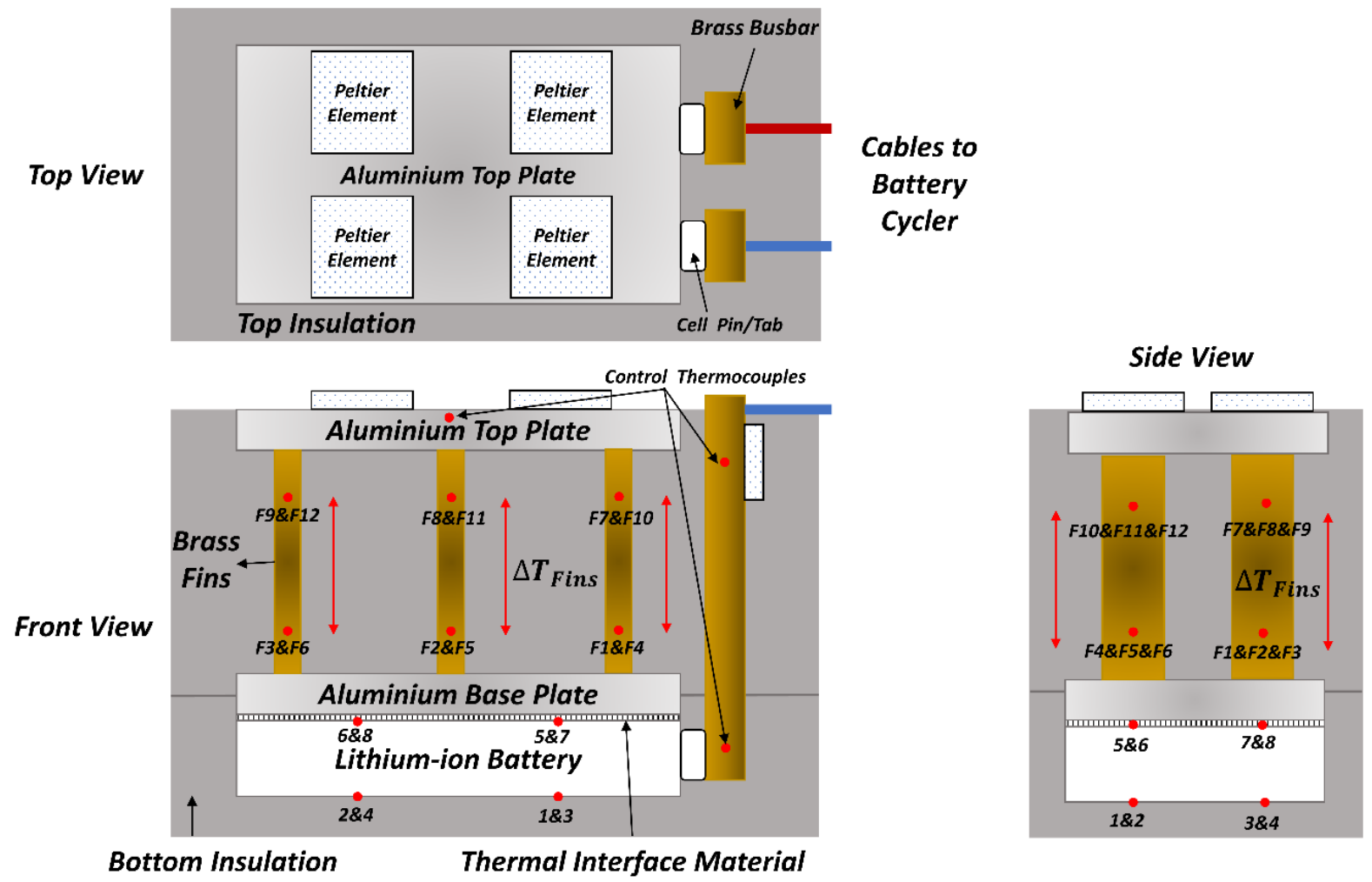

Fig.5: Experimental testing rig for Cell Cooling Coefficient tests and thermocouple locations for the cell.

A pristine cell from the same manufacturer \& the same batch is investigated in this section. A schematic of the experimental testing rig used for the CCC experiments is shown in Fig. 5. The cell pins are connected with two brass busbars and sit within the bottom insulation shell. All the thermocouples attached to the testing rig were adhered using thermal epoxy (1.22 $\mathrm{W} \cdot \mathrm{m}^{-1} \mathrm{~K}^{-1}$ ), unless specifically stated. Temperature mesurements were recorded using four 
Pico Technology data loggers (Model: TC-08) with K-type thermocouples. The entire testing rig sat on the bottom shelf of a thermal chamber (Binder, model KB400), with forced convective air control. One end of each brass busbars is connected to the cell, using ring terminals. On the other end, the busbars are connected to the battery cycler (Maccor, Model: Series 4000) with ring terminals attached to two copper wires (insulated copper wires with a radius of $7.5 \mathrm{~mm}$ ) accordingly. At both ends of the brass busbars, the set-up was tightened using set screws, to a $12 \mathrm{Nm}$ with a torque wrench. This configuration set-up was found to minimise electrical resistance. In the results and discussion section, the featured model still considers the extra electrical resistance caused by the set-up.

There are four thin-leaf K-type TCs (TC 6-8) placed on the top surface and held in place with thermally condictive kapton tape. TC 6-8 had a thickness of just $50 \mu \mathrm{m}$ and a width of $3.2 \mathrm{~mm}$. Such small thickness ensures a flat and even contact between the aluminium base plate and the cell. There is also a layer of $0.5 \mathrm{~mm}$ thick thermal interface gel $\left(8 \mathrm{~W} \cdot \mathrm{m}^{-1} \mathrm{~K}^{-1}\right)$ between these 2 interfaces for an improved consistency. The TC 1-4 were adhered to the bottom surface of the cell.

The top and bottom aluminium plates are identical, with the same surface area as the cell (200.5 x $130.3 \mathrm{~mm}$ ), and a thickness of $19 \mathrm{~mm}$. These aluminnium plates (Aliminium alloy 6082T6) have a high thermal conductivity $\left(180 \mathrm{~W} \cdot \mathrm{m}^{-1} \mathrm{~K}^{-1}\right)$, which ensure a uniform cell surface temperature and uniform heat distribution through 6 fins. The six brass fins were adhered into the base and top plates slots $(5 \mathrm{~mm})$, with a length of $90 \mathrm{~mm}$ individually. Therefore, the adjacent faces of the top and base aluminium plates are $80 \mathrm{~mm}$ away from each other. Each cell side TC ( TC_F1-6) are located 65 mm from its corresponding controlside TC (TC_F7-12).

The insulation material used was milled Styrofoam $\left(0.033 \mathrm{~W} \cdot \mathrm{m}^{-1} \mathrm{~K}^{-1}\right)$, to ensure a purely conductive system bounded by the insulation's exposed faces. The Peltier elements (PE) were attached and adhered to the top surface of the top aluminium plate as well as the top end of the brass busbars. PE were used to set the control temperature of the system. The PE on the aluminium cooling plate maintain a consistent thermal boundary condition. The PE on the busbars aim to match the cell temperature, in order to minimise heat transfer along the busbars (i.e. avoidable errors). Unavoidable heat loss through the insulation, wires, 
gaps/holes for wires was minimised but accounted in the simulation and data analysis.

The experimental procedure is based on previous work $[5,15]$, where the cell underwent a square wave pulsing current profile at $1 \mathrm{~Hz}$ for heat generation, with a zero average current input, and the SoC of the cell is checked before and after experiments to ensure there is no drift. Therefore the SoC of the tested cell oscillates within a narrow range around a constant of $50 \%$. A total of 6 current magnitude are tested in this study, which induced varying rates of heat generation in the tested cell. The current magnitudes are $0.67 \mathrm{C}(60 \mathrm{~A}), 1 \mathrm{C}(90 \mathrm{~A}), 1.11 \mathrm{C}$ $(100 \mathrm{~A}), 1.22 \mathrm{C}(110 \mathrm{~A})$ and $1.33 \mathrm{C}(120 \mathrm{~A})$. The detailed testing procedure is presented in the supplementary material A, and the detailed current profile is introduced in Fig.9.

\section{Results and discussion:}

\subsection{Adiabatic condition validation}

The boundary conditions detailed in section 3.1 and 3.2 were reproduced in the simulation, with a cell discretisation of L4 x W6 x T8 (192 nodes). In Fig.6(a), the input current is shown, Fig.6(b) and 6(c), demonstrate the corresponding measured \& simulated terminal voltage data and simulated results. For the electrical model, a good alignment between experimental data and the simulated results is shown, which delivers an overall RMSE of 8 $\mathrm{mV}$. The large error spikes at time step of 2500s $(29.81 \mathrm{mV})$ and $3400 \mathrm{~s}(23.97 \mathrm{mV})$ are from long resting periods with no current input. The priority of this work was accuracy under load, when heat is generated, to validate the discretised thermal model. Therefore, the electrical model is considered acceptable.

Fig.6(d). and 6(e), present the measured and simulated cell surface thermal behaviours, specifically at the cell surface centre and the cell positive \& negative terminals (TC_C1, TC_P1-P2 in Fig.3). It is shown that across the entire cell surface, the model is able to capture the temperature distribution well with a RMSE of $0.16{ }^{\circ} \mathrm{C}, 0.38{ }^{\circ} \mathrm{C}$ and $0.99{ }^{\circ} \mathrm{C}$ at cell surface centre, cell positive terminal and negative terminal, respectively. The results indicate that the overall cell stack heat capacity (together with the insulation and power cables) simulated in the model matches well with the experimental set-up. Therefore, the model is considered acceptable for implementing the more dynamic thermal analysis for the 
CCC.
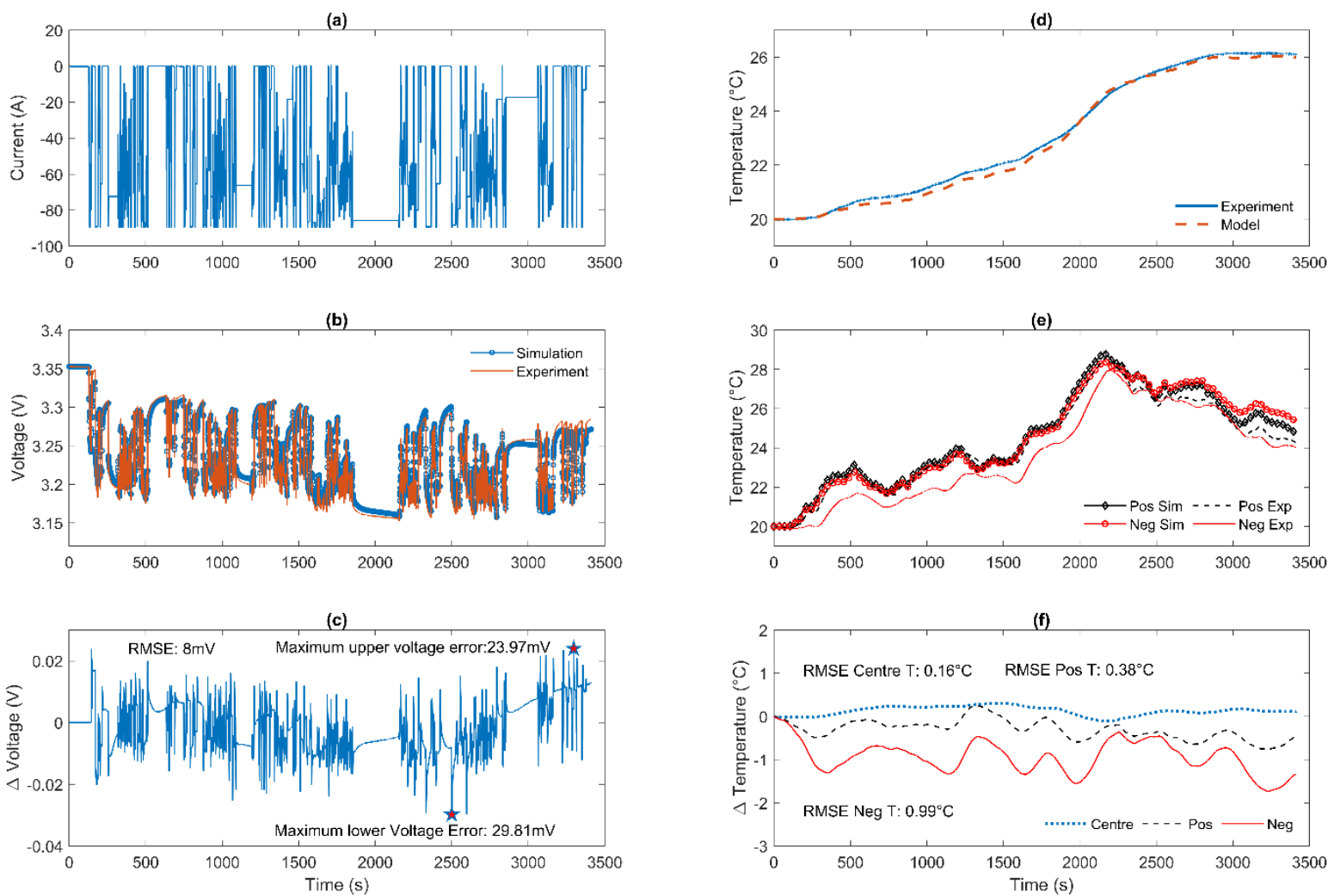

Fig. 6: Electrical Model validation results for adiabatic condition (a-c), where a RMSE of cell terminal voltage of $8 \mathrm{mV}$ is achieved: (a) Input Current, (b) Terminal Voltage: Experimental data vs model simulation, (c) Delta voltage error between simulation and experimental data, and Thermal model validation results for adiabatic condition (d-f), where the cell surface temperature RMSE of $0.16^{\circ} \mathrm{C}$, positive pin temperature RMSE of $0.38{ }^{\circ} \mathrm{C}$ and negative pin temperature RMSE of $0.99^{\circ} \mathrm{C}$ are achieved: (d) Cell surface centre temperature Experimental data vs model simulation, (e)Cell terminal temperatures Experimental data vs model simulation, (f) Delta temperature error between simulation and experimental data for (d) and (e).

With the benefits of three-dimensional modelling, the ability to investigate thermal gradients in different directions is achieved. Fig.7(a) and 7(b), describe the 2D internal temperature profiles shown in Fig.8. (a)-(c) and (d)-(f) accordingly. Fig.8(a)-(c) present the thermal distribution of the central jellyroll layer (e.g. x-y axis). At the beginning of the drive cycle, 
the cell is fully charged and reaches thermal equilibrium at $20^{\circ} \mathrm{C}$. While the cell underwent the drive cycle input current, the entire internal temperature level rises while the hottest region gradually evolves near the top part of the cell, as indicated in Fig. 8(b). This large amount of heat is generated from the large value of current load through the internal resistance of the cell terminals and power cables. At the end of the drive cycle shown in Fig. $8(\mathrm{c})$, the heat is generated, accumulated and propagated to the centre of the cell. In Fig.8(d)-(f), the cross-sectional thermal distribution (e.g. $\mathrm{x}-\mathrm{Z}$ axis) is demonstrated. Similar phenomena are observed here, where the hottest region is the centre of the jellyroll. However, the largest thermal gradient is less than $0.2{ }^{\circ} \mathrm{C}$ in such near adiabatic condition. In the CCC analysis, larger thermal gradient is artificially generated for a better understanding of thermal management under more aggressive operating conditions.

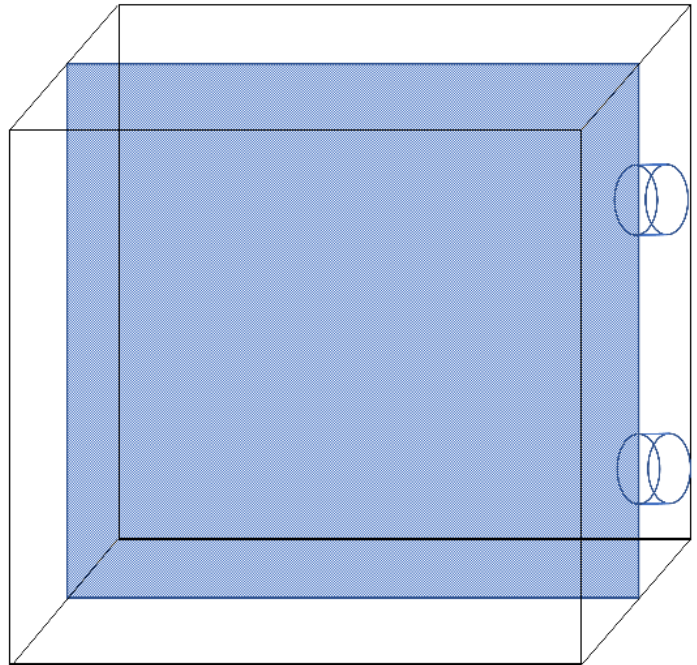

(a)

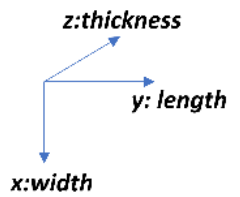

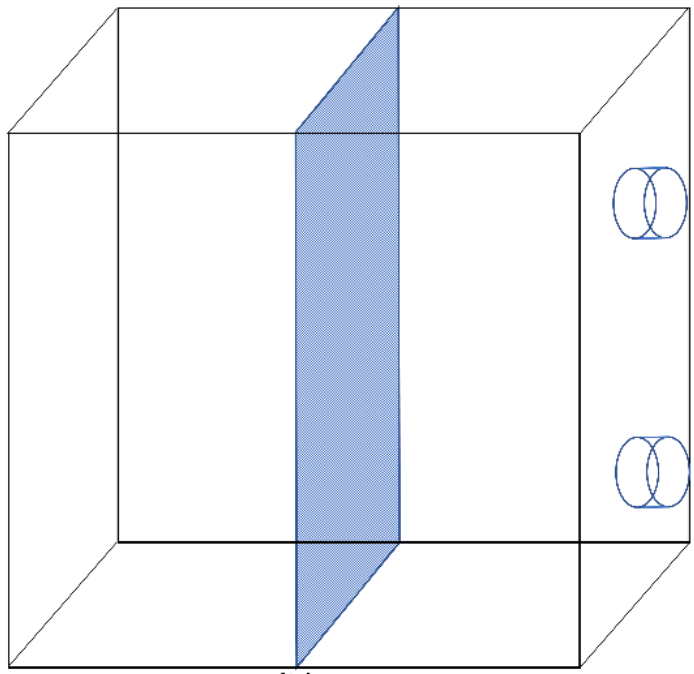

(b)

II Domain

Simulation Domain

Fig. 7: Cell internal state domain \& simulation domain demonstration: (a) $x$-y axis interface, (b) $x-z$ axis interface. 

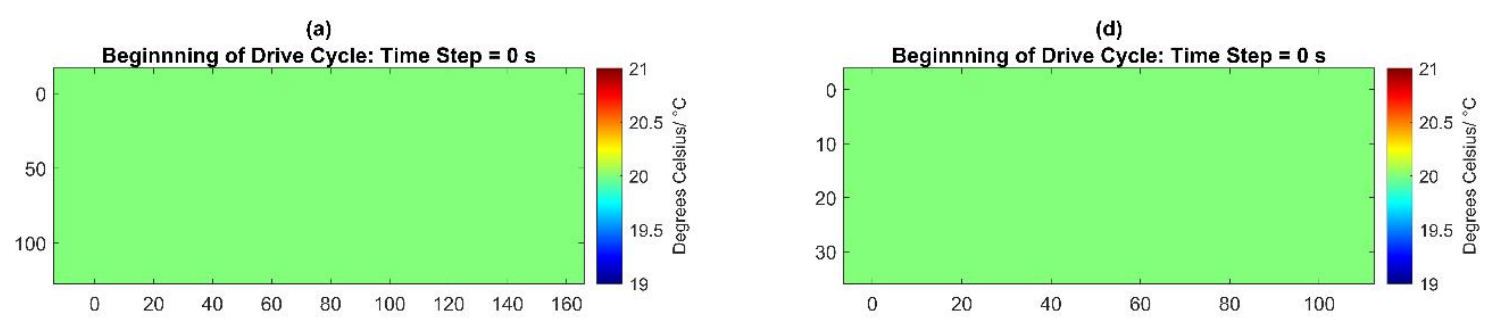

(b)
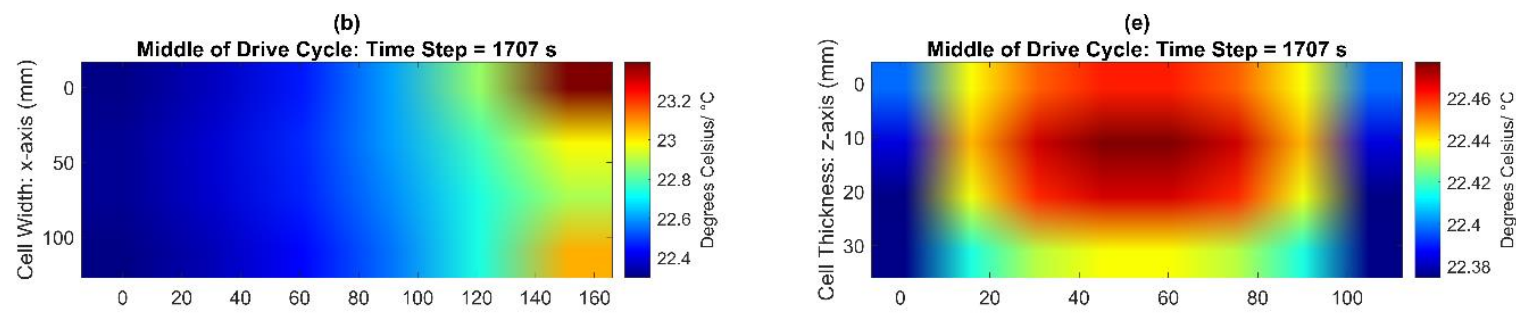

(c)
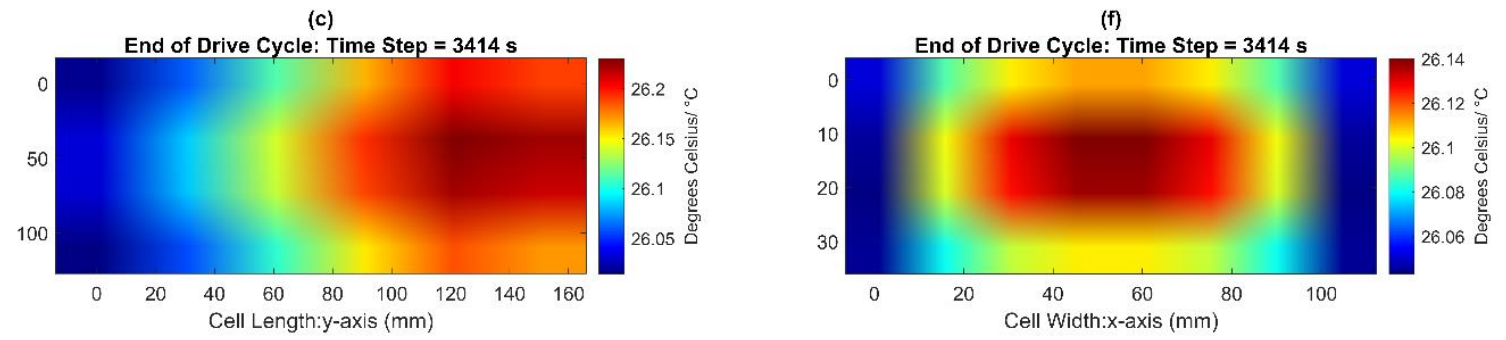

Fig.8: Simulation results for adiabatic condition, cell internal temperature distribution in $x-y$ axis domain (a)-(c): (a) at beginning of the drive cycle, where $t=0 \mathrm{~s}$, (b) at middle of the drive cycle, where $t=1707 \mathrm{~s},(\mathrm{c})$ at end of the drive cycle, where $t=3414 \mathrm{~s}$; in $x-z$ axis $(d-f)$ domain (d) at beginning of the drive cycle, where $t=0 \mathrm{~s}$, (e) at middle of the drive cycle, where $t=1707 \mathrm{~s},(f)$ at end of the drive cycle, where $t=3414 \mathrm{~s}$.

\subsection{Cell Cooling Coefficient Validation}

The cell has been tested using CCC square wave heat generation testing procedure, using currents from $45 \mathrm{~A}$ to $120 \mathrm{~A}$, while the model has been amended into the same boundary conditions as showed in Fig.5. The inputs for the model include input current recorded from the battery cycler, the ambient temperature of the thermal chamber, the controlled temperature at the aluminium top plate and the loss to the environment of the cell heat generation, due to the imperfect insulation.

The apparatus is characterized in the same method as the previous works [5,15], achieving a $76.3 \%$ efficiency of desired heat pathways compared to undesired. This is significantly lower than previous measurements for a pouch cell with smaller surface area $(94.6 \%$ for a $5 \mathrm{Ah}$ Kokam High Power Pouch cell SLPB11543140H5 [15], based on similar apparatus with a 
smaller size). This is because the larger surface area and the higher thermal conductivity of the metallic casing of prismatic cells introduces significantly larger undesired losses. However, these losses can still be accounted for. In this work, low currents were used to reduce the heat generation rate, and therefore achieve a more precise heat generation rate captured through the brass fins.

In Fig.9, the experimental data and simulation results for the voltage response for the pulsing current are presented, with a good match between measured and simulated values where a RMSE of $2.6 \mathrm{mV}$ is achieved. As mentioned in the parameterisation section in the supplementary material A, the underload RC network parameters deliver good fitting for the test like CCC (pure constant current underload), as the focus of this work is essentially on the estimation of loss power generation, and therefore heat generation.

In Fig.9(c), the shrinking voltage range over time is due to the relationship between the cell internal resistance and temperature. As the heat generation pulsing test is ongoing, the average temperature of the cell increases, decreasing cell internal resistance. As a result, the voltage operating range decreased. After a certain amount of time (e.g. 20,000 s), the cell reached the thermal steady state, where the cell average temperature, the cell internal resistance and the voltage operating range stabilised. 


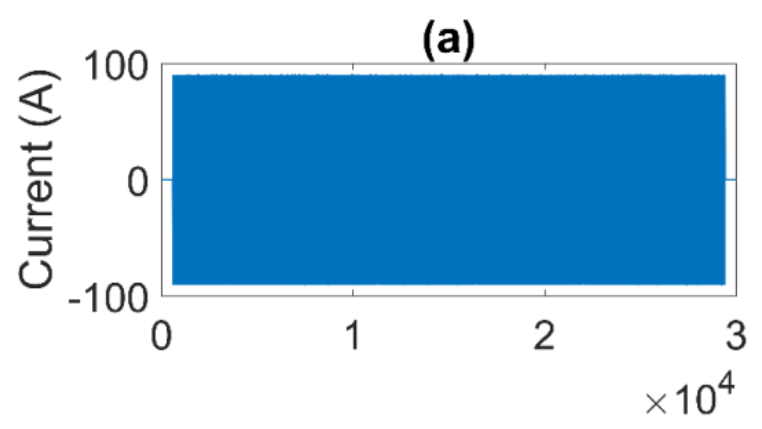

(c)
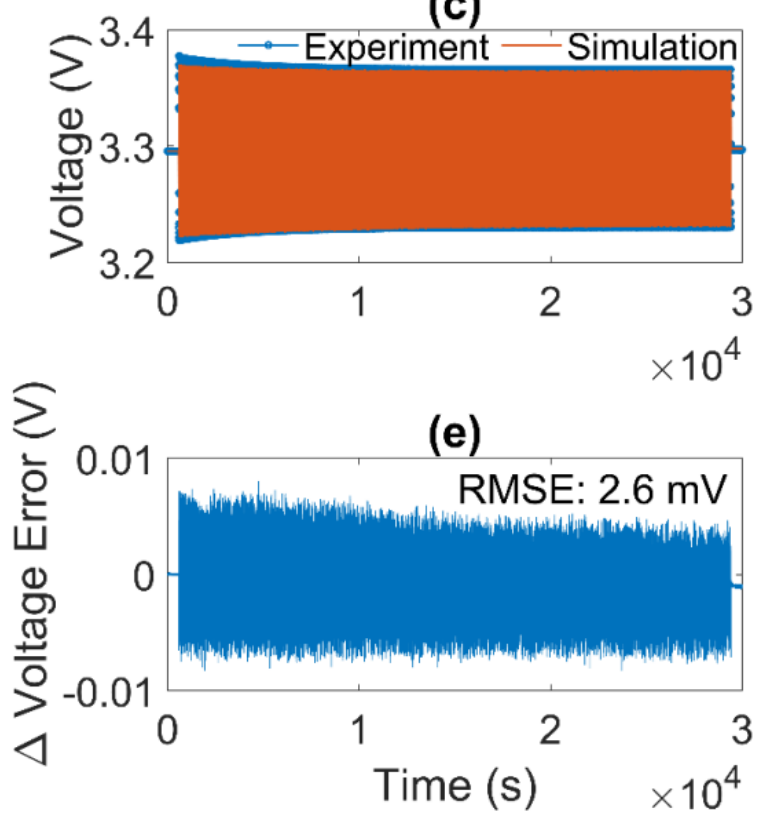

(b)

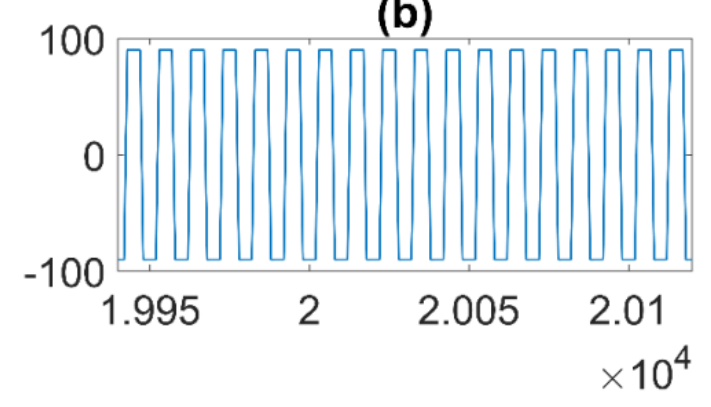

(d)

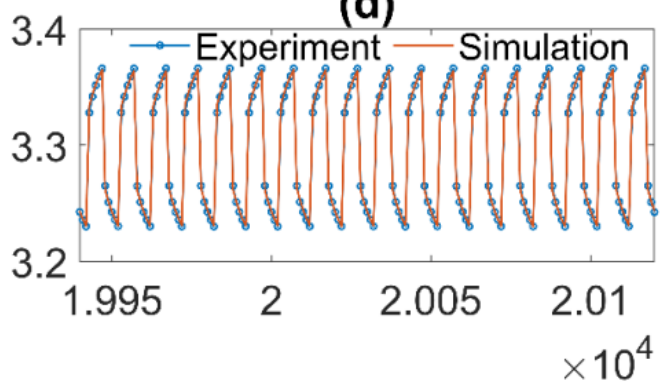

(f)

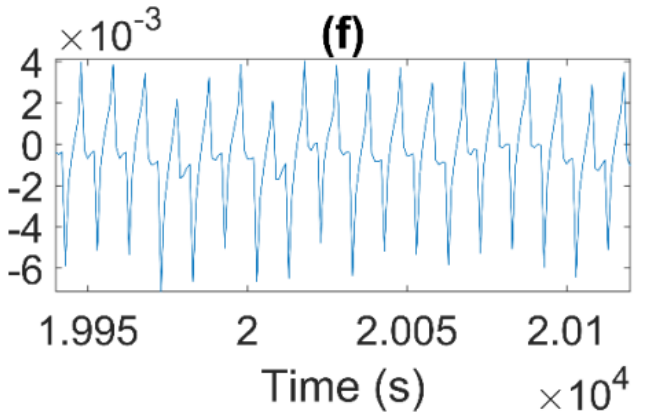

Fig.9: Validation results for CCC Pulsing heat generation tests at 90A, where a RMSE of cell terminal voltage of $2.6 \mathrm{mV}$ is achieved: (a) Input Current, (c) Terminal Voltage: Experimental data vs model simulation, (e) Delta voltage error between simulation and experimental data; (b), (d) \& (f) are the zoomed segment of data from Time =19940 s to $20110 \mathrm{~s}$ for (a), (c) \& (e) respectively.

Determination of the CCC metric requires that the rate of heat generation within the cell is equivalent to the heat rejection from the cell when the system reaches its thermal steady state. Further, another critical assumption has been made in this work, based on the previous published work [15], that the convective heat transfer is negligible within the apparatus. The airflow within the system (around the cell) was eliminated by the insulation, making this assumption justified. This boundary condition has been set into the model as well. The average cell surface back and front temperature $\bar{T}_{\text {Back }}$ and $\bar{T}_{\text {Front }}$ can be calculated in Eqn. (17) and Eqn. (18): 


$$
\begin{aligned}
& \bar{T}_{\text {Back }}=\frac{T_{T C 1}+T_{T C 2}+T_{T C 3}+T_{T C 4}}{4} \\
& \bar{T}_{\text {Front }}=\frac{T_{T C 5}+T_{T C 6}+T_{T C 7}+T_{T C 8}}{4}
\end{aligned}
$$

The temperature difference across the cell, $\Delta T_{\text {Cell }}$, is the difference between the mean back surface temperature with the mean front surface temperature:

$$
\Delta T_{\text {Cell }}=\bar{T}_{\text {Back }}-\bar{T}_{\text {Front }}
$$

Eqn. (20) and (21) summarise the rate of heat transfer through each fin (1-6), and the sum of the heat rates from all the fins delivers the conductive heat transfer through the front surface of the cell, $\dot{Q}_{\text {Surf }}$ :

$$
\begin{gathered}
\dot{Q}_{f n}=\frac{k_{f n}}{x_{f n}} \times A_{f n} \times \Delta T_{f n}, n=1-6 \\
\dot{Q}_{\text {surf }}=\sum_{6}^{n=1} \dot{Q}_{f n}
\end{gathered}
$$

The ratio of the front surface heat transfer rate with the thermal gradient across such cell defines the cell cooling coefficient for single surface cooling, $C C C_{\text {surf }}$ :

$$
C C C_{\text {surf }}=\frac{\dot{Q}_{\text {surf }}}{\Delta T_{\text {Cell }}}
$$

There is a great fit overall for the entire experiment, in both transient and steady state region. The model quantitatively simulated the heat generation as well as the temperature gradient of the tested cell. Fig.10 demonstrates the experimental and simulated thermal results for the 90 A CCC test. The temperature gradient generated from the testing apparatus is shown in Fig.10(a). It is shown that with $1 \mathrm{C}$ charge and discharge pulsing rate, there is a $1.51{ }^{\circ} \mathrm{C}$ thermal gradient across the cell thickness in z-axis. The simulation and experimental results align well with each other with a RMSE below $0.4{ }^{\circ} \mathrm{C}$ for both surfaces. The thermal gradient simulation shows a good fit of RMSE below $0.1^{\circ} \mathrm{C}$, which builds a foundation for an accurate CCC simulation. The CCC simulation shows a $0.4 \mathrm{~W} / \mathrm{K}$ RMSE due to the relatively large error occur in the heat transfer rate simulation, where the RMSE of Q surface is $0.49 \mathrm{~W}$. 
(a)

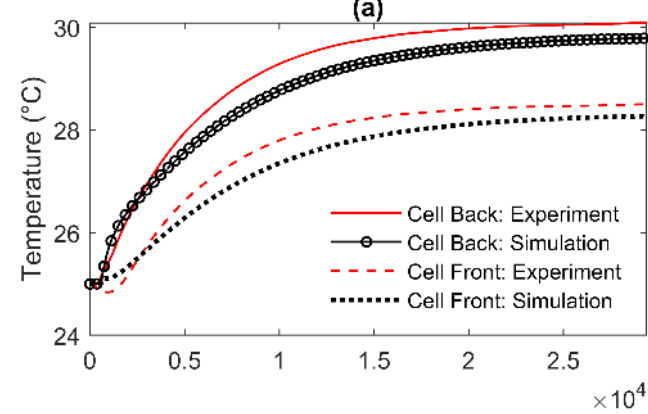

(c)

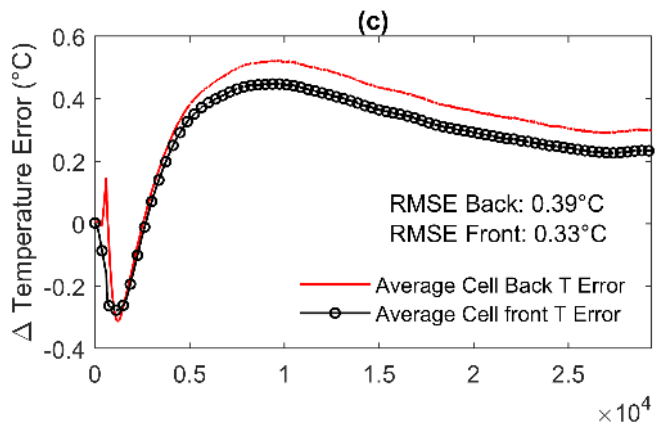

(e)

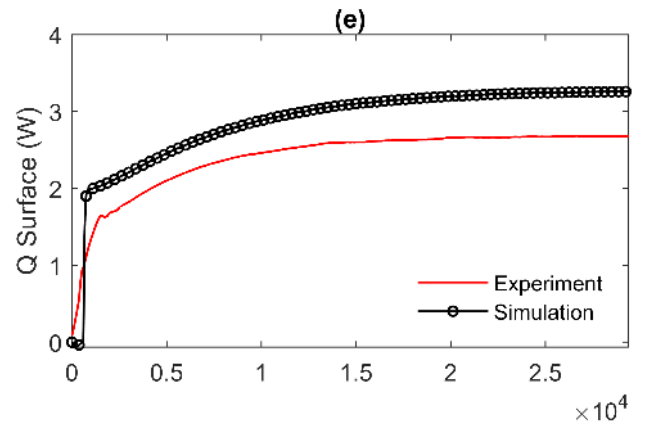

(g)

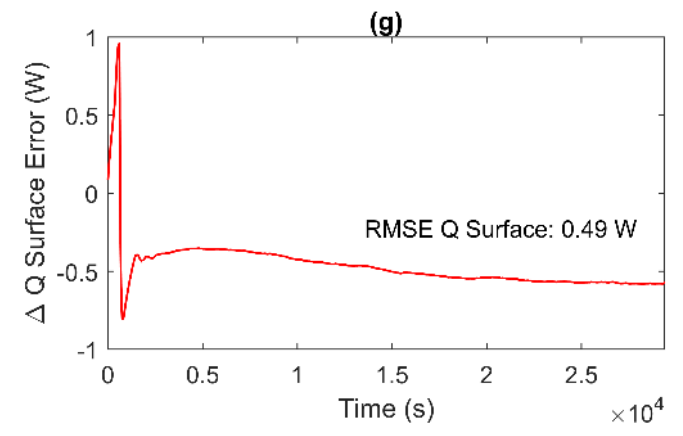

(b)

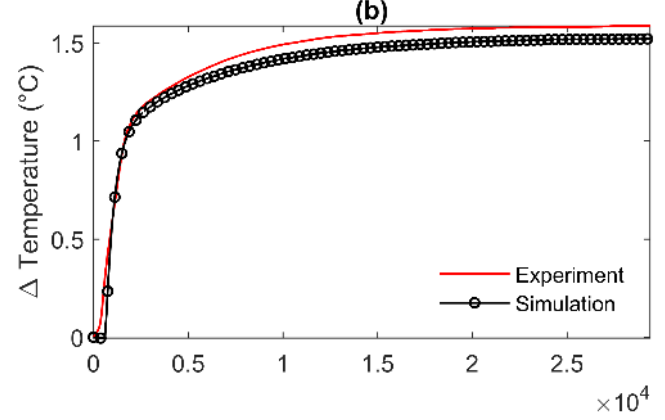

(d)

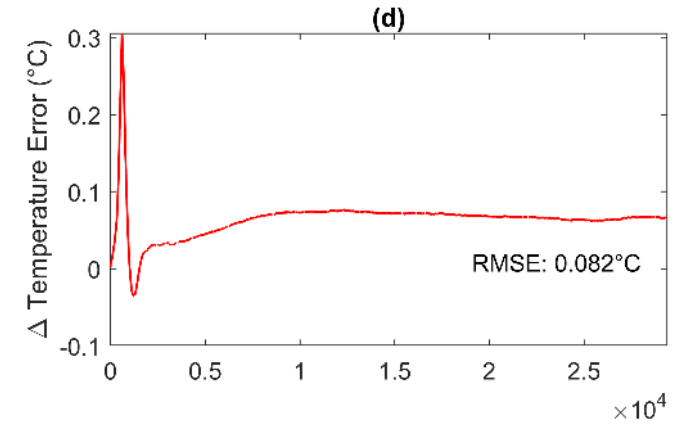

(f)

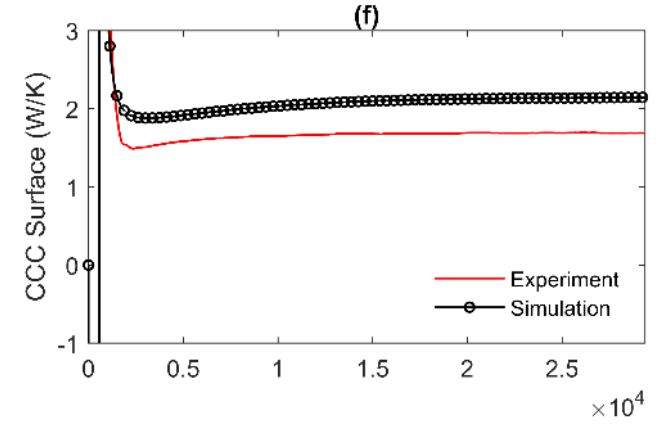

(h)

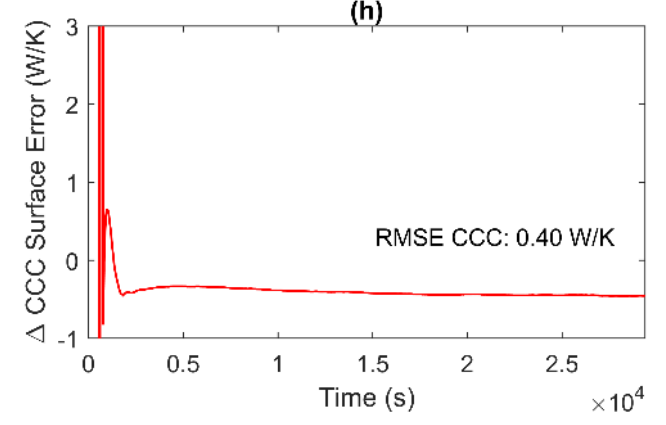

Fig.10: Validation results for CCC Pulsing heat generation test at 90A, where a RMSE of cell front \& back temperature of $0.33{ }^{\circ} \mathrm{C} \& 0.39^{\circ} \mathrm{C}$, the RMSE of the delta $\mathrm{T}$ of $0.082^{\circ} \mathrm{C}$, the

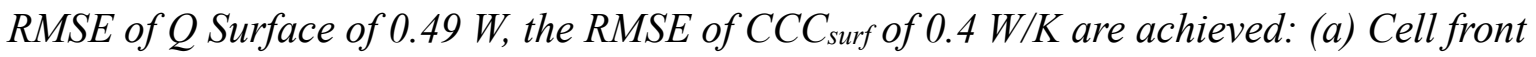
and back temperature: Experimental data vs model simulation, (b) Delta temperature between cell front and back temperature: Experimental data vs model simulation, (c) \& (d): corresponding error plots for (a) \& (b); (e) Sum of the $Q$ surface through brass fins: Experimental data vs model simulation, (f) $C C C_{\text {surf }}$ of the cell: Experimental data vs model simulation, $(g) \&(h)$ : corresponding error plots for $(e) \&(f)$. 
(a)

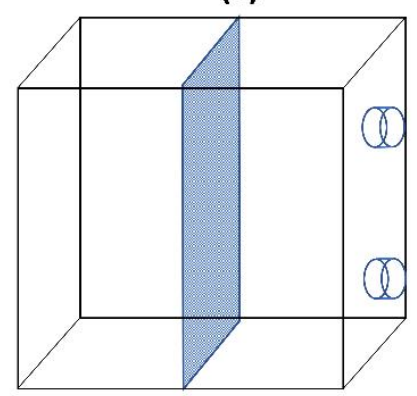

(c)

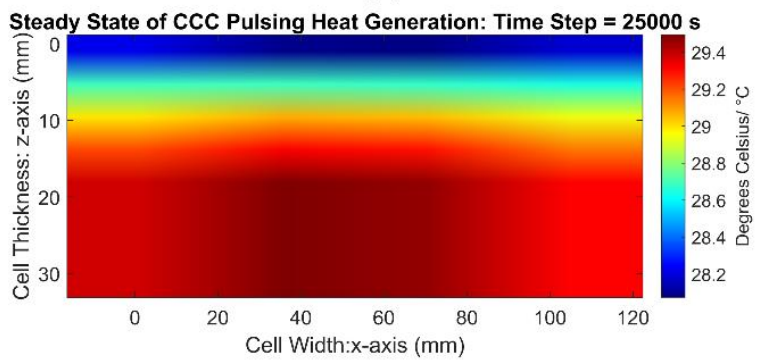

(b)
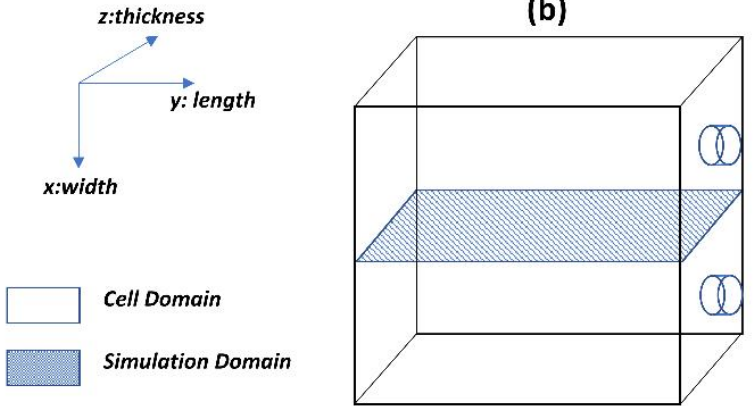

(d)

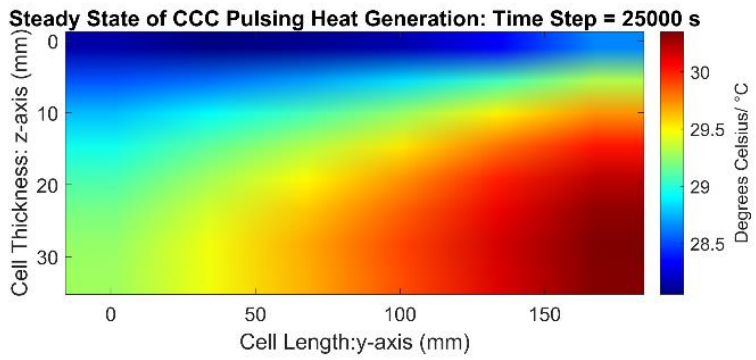

Fig. 11: Cell internal state domain \& simulation domain demonstration \& Simulation results for $90 \mathrm{~A}$ CCC pulsing heat generation, cell internal temperature distribution at thermal steady state where $t=25000 \mathrm{~s}$, in: $(a \& c) x$ - $z$ domain, $(b \& d) z-y$ domain.

Fig. 11 demonstrates the simulation domain and results for the internal thermal state of the 90 A CCC experiments at time step of 25,000 s. The largest surface of the cell is attached to the CCC apparatus, where the heat rejection from the cell induces a thermal gradient across the cell thickness, z-axis. In Fig.11(c), the model shows that an evenly distributed thermal gradient in the $\mathrm{x}-\mathrm{z}$ domain has been simulated, with a validated $\Delta T_{\text {Cell }}$ above $1.5^{\circ} \mathrm{C}$. In Fig.11(d), the model suggests that the region near the current collector welding points have the hottest operating temperature at thermal steady state. This is due to the large resistance of the welding and casing connection during manufacturing. The four control TCs and PEs on the busbar showed in Fig. 5 aimed for a constant temperature at the busbar and therefore decreased the thermal gradient along the cell length to less than $1 \mathrm{~K}$.

However, the effect of the cell terminals cannot be entirely eliminated and therefore can still be seen in the simulation domain, particularly as both cell terminals are located on the same side of the cell. The trade-off between the manufacturing/battery pack assembling convenience with a thermal gradient along the cell length is therefore apparent. A previous study conducted by Zhao et al. [31] showed that cell terminals on opposite sides will significantly lower the thermal gradient along the cell length. 
The simulated results of the internal thermal gradient suggest a similar logic, where the large format prismatic cells lead to large internal thermal gradients. Further, operating the cell at higher $\mathrm{C}$ rates lead to higher average operating temperature as well as higher thermal gradient across cell layers, which will therefore lead to accelerated degradation. Fig.12(a) demonstrates the simulated internal thermal gradient across the cell thickness in z-axis at various currents. Fig.12(b). shows a good agreement of the $\Delta T_{\text {Cell }}$ between simulations and experiments, with an overall RMSE of less than $0.9 \mathrm{~K}$. The relationship between the pulsing current and the dealt $\mathrm{T}$ is almost linear in both simulations and experiments.

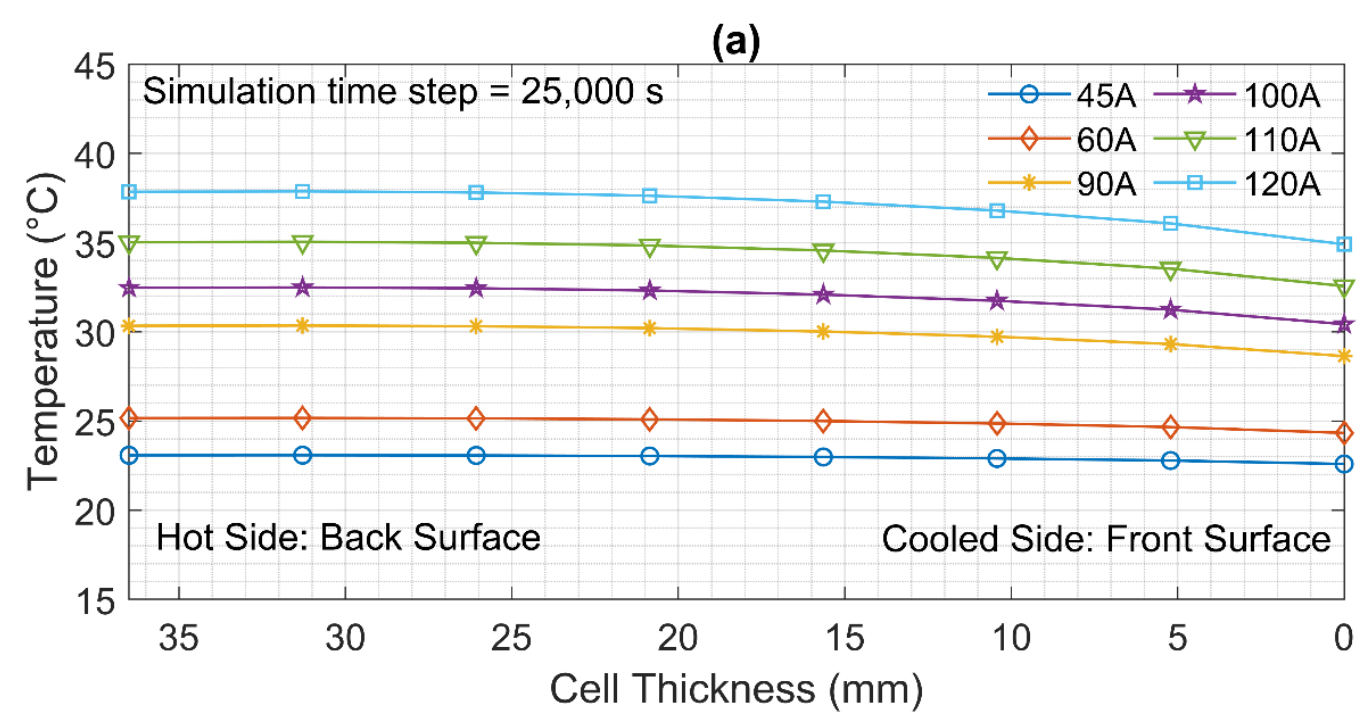

(b)

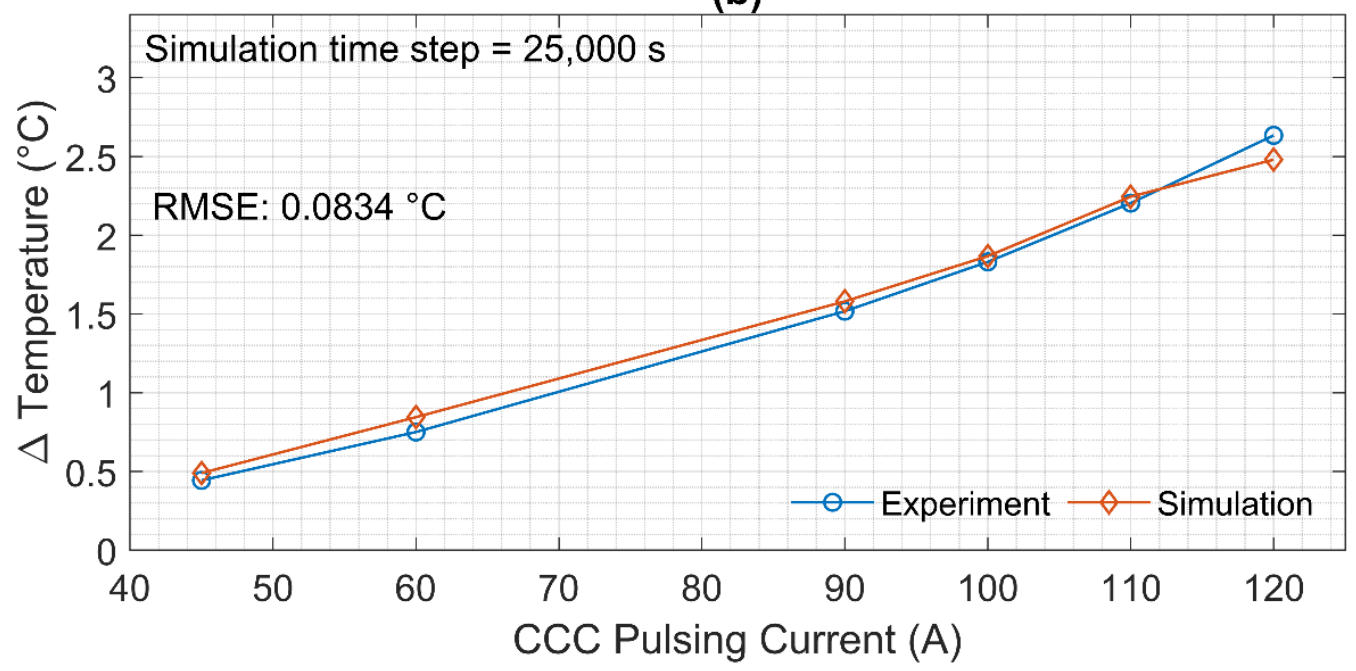

Fig.12: Thermal gradient across cell surface in z-axis at 45A, 60A, 90A, 100A, 110A and $120 A$ (a): Simulation results of internal thermal gradient for CCC pulsing heat generation, (b)Delta average surface temperature: Simulation vs Experiment. 


\subsection{Cell Cooling Coefficient Analysis and Cell Optimisation}

\subsubsection{Zero Ampere Cell Cooling Coefficient Analysis}

In Fig.13, the experimental and simulated derived $C C C_{\text {surf }}$ values at various currents are shown. An overall RMSE of $0.41 \mathrm{~W} / \mathrm{K}$ is achieved. A linear trend is captured for both cases: the $\mathrm{CCC}$ is negatively proportional to the pulsing current. Also, one noticeable phenomenon is observed that, in the large value of input currents (e.g. $90 \mathrm{~A}, 100 \mathrm{~A}, 110 \mathrm{~A} \& 120 \mathrm{~A}$ ), the change in both simulated and measured CCC is small. The vertical error bars indicate the errors from experimental measurements of the K-type TCs $( \pm 0.01 \mathrm{~K})$, which results in a larger error in the $C C C_{\text {surf }}$ calculation when the $\mathrm{Q}$ surface is small (current input is small).

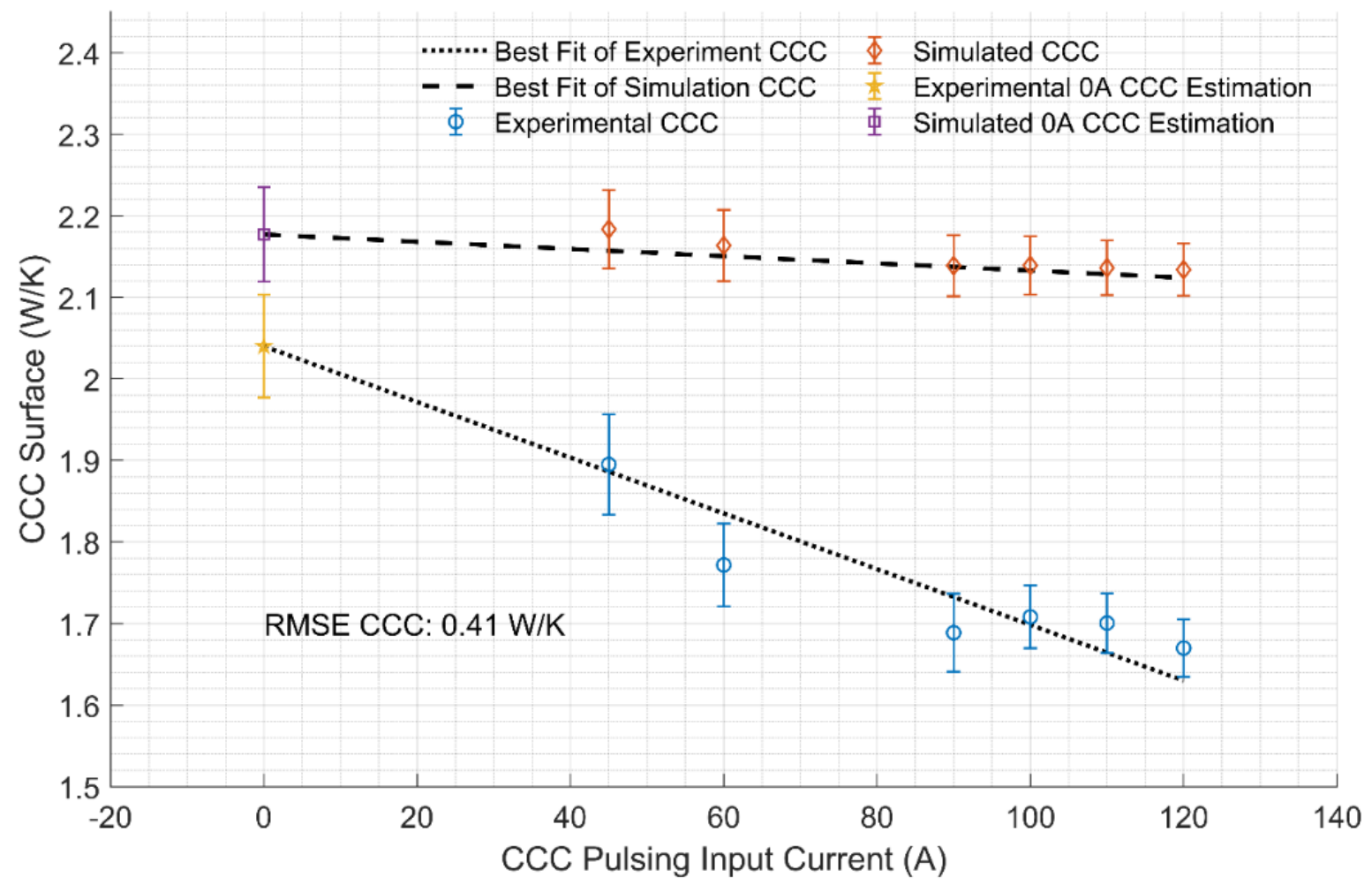

Fig. 13: The derived $C C C_{\text {surf }}$ for all experimental tests and simulation, plotted against the pulsing input currents at 45 A, 60 A, $90 \mathrm{~A}, 100 \mathrm{~A}, 110 \mathrm{~A}$ and $120 \mathrm{~A}$ with error bars. A linear least square line of best fit in included for each dataset, where the point of interactions with 0 A input current are marked. The RMSE of $C C C_{\text {surf }}$ between experimental data and simulation is $0.41 \mathrm{~W} / \mathrm{K}$, the $0 \mathrm{~A} \mathrm{CCC}$ surf indicated a value between 2.04 to $2.18 \mathrm{~W} / \mathrm{K}$ from experiments and simulation respectively. 
Similar to the previous work [15], the hotter bottom layers of the cell, as shown in Fig. 11, reject a certain amount of heat through the tabs. This reduces the heat flux through the electrode-stack from the bottom layers to the top layers \& subsequently the cell top surface. Consequently, a reduced $\Delta T_{\text {Cell }}$ presents higher values of $C C C_{\text {surf }}$ at lower input pulsing current (e.g. 45 A \& 60 A). This explains the decreasing trends for both simulated and measured $C C C_{\text {surf. }}$ Lower input pulsing current experiments achieved a higher value of $C C C_{\text {surf }}$, as the signal-to-noise ratio for higher current is high. This explains the different bias level and slopes of $C C C_{\text {surf }}$ between simulated and measured data in Fig. 13. As in the model, the busbars are considered as passive heat dissipation components, where there is no heat flux transmitted into the cell. This leads to a smaller influence of the simulated busbars and therefore reduced difference in $C C C_{\text {surf }}$ magnitude in different $\mathrm{C}$ rates.

The non-linearity of the insulation efficiency causes the different slopes of $C C C_{\text {surf }}$ values in Fig.13. In all the CCC studies (including this one), the insulation efficiency is a single value which is used in various input currents and heat generation rates. In fact, larger heat generation causes a larger thermal gradient between the thermal chamber ambient temperature and the cell temperature, which leads to larger losses. This explains further why the simulation and the experiments deliver different slopes in CCC, as larger current experiment underwent a higher loss to the environment, where the simulation did not. A potential future work where a precise loss efficiency function is measured at different heat generation rates could be conducted to eliminate this issue.

The error analysis is validated through the linear extrapolation towards 0 A of input current. (here Matlab function 'lsqlin' is used), assuming there is no heat generation from all the components in the apparatus, which eliminates all the errors. Values of $2.18 \mathrm{~W} / \mathrm{K}$ and 2.04 $\mathrm{W} / \mathrm{K}$ are captured for simulation and experiment respectively. These $0 \mathrm{~A} C C C_{\text {sur }}$ values or in other words the 'True $C C C_{\text {surf' }}$ 'represent the cell's capability to be thermally managed, when external factors such as unwanted heat loss or ohmic heating at busbar contacts is eliminated. The model predicts the true $C C C_{\text {surf }}$ value with a RMSE of $0.14 \mathrm{~W} / \mathrm{K}$. It suggests that the model enhanced the $\mathrm{CCC}$ analysis by simplifying the true $\mathrm{CCC}$ identification process, and validated the experimental true CCC analysis method proposed previously[15]. Here, a reliable true $\mathrm{CCC}$ value for the target cell is achieved through implementing few key 
boundary conditions into the model, with reduced cost and time.

\subsubsection{Cell Optimisation}

By modifying a few of the essential cell parameters within the developed model (e.g. casing material, cell thickness), cell optimisation can be conducted. The $C C C_{\text {surf }}$ can be used as the critical evaluation metric in order to redesign a cell for better thermal management.

\section{Casing Material Analysis}

In Fig.14(a), four casing materials are investigated using the same battery jellyroll electrode stack, meaning the same internal heat generation rate at same input CCC pulsing currents. The detailed casing material thermal parameters are introduced in Table 3.

(a)

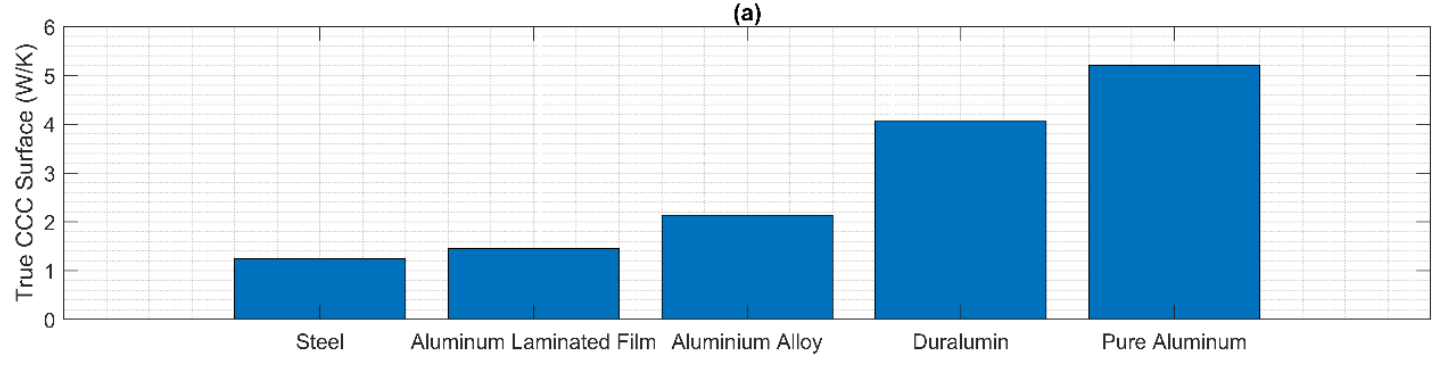

(b)

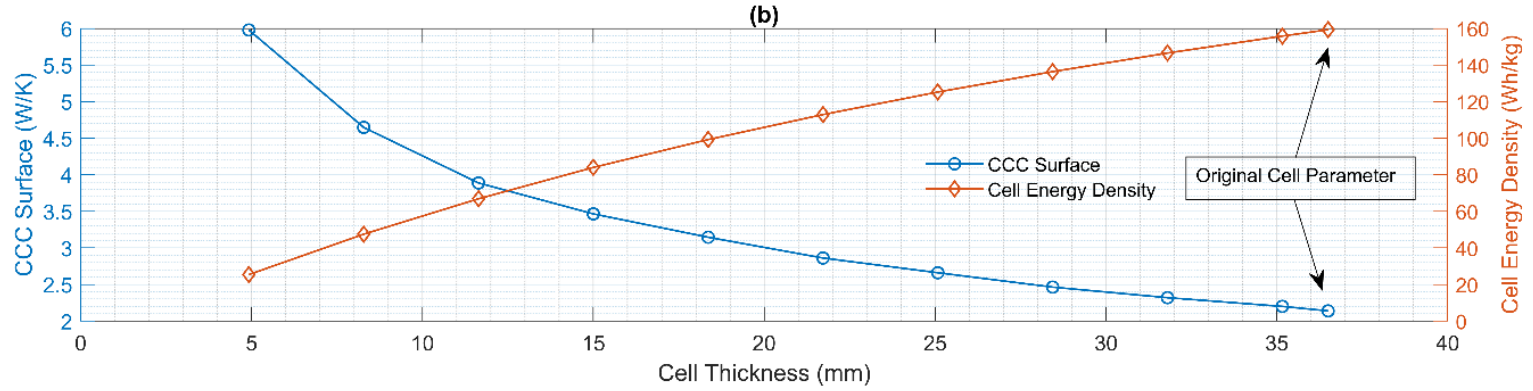

(c)

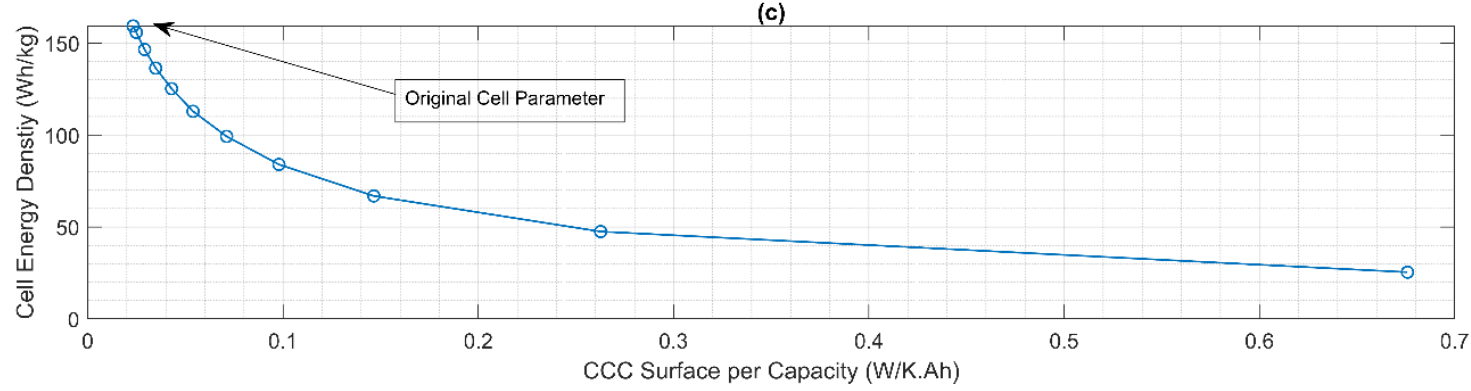

Fig. 14: Cell optimisation: (a) The derived true CCC $C_{\text {surf }}$ of simulation using different casing materials (Aluminium Alloy, Steel, Aluminium laminated film, Duralumin and Pure aluminium) with the same internal jellyroll electrode stack; The derived $C C_{\text {surf }}$ of simulation at different cell thickness: (b) The $C C C_{\text {surf }}$ values and cell energy density at different cell thickness values, (c)the derived cell energy density plots against $C_{C} C_{\text {surf }}$ per Cell Capacity. 
The Steel casing has the largest value of density compared with other analysed casing material, which leads to low casing material mass to the active material ratio. Consequently, steel plays a minor role in the prismatic battery manufacturing due to the low energy density compares with other lighter material. The $C C C_{\text {surf }}$ analysis demonstrates the effect of its low thermal conductivity, with a $C C C_{\text {surf }}$ value of around $1.24 \mathrm{~W} / \mathrm{K}$. By contrast, both pure aluminium and duralumin (aluminium alloy with improved strength) delivers significantly higher $C C C_{\text {surf }}$ values, of $5.2 \mathrm{~W} / \mathrm{K}$ and $4.1 \mathrm{~W} / \mathrm{K}$ respectively. However, pure aluminium's hardness is lower compared to many alloy materials, making alloy materials a better choice for prismatic cell casing, which considers both mechanical safety and thermal management capability. For comparison purposes, aluminium laminated film was also simulated, providing a $C C C_{\text {surf }}$ value around $1.45 \mathrm{~W} / \mathrm{K}$, which explains why pouch cells are typically far thinner than prismatic cells. These simulation results explain why a metallic casing for large format prismatic cells is necessary for thermal management, however it also provides ceiling on single cell energy density because of its weight. Therefore, a light, hard and with high thermal conductivity casing material is the ideal. The experimental validation of various casing material is out of this study's scope but would be interesting future work.

Table 3: Thermal Properties for different casing material.

\begin{tabular}{ccccc}
\hline Casing Material & $\begin{array}{c}\text { Density } \\
{\left[\mathbf{k g} / \mathbf{m}^{3}\right]}\end{array}$ & $\begin{array}{c}\text { Thermal } \\
\text { Conductivity } \\
\text { [W/ (m.K)] }\end{array}$ & $\begin{array}{c}\text { Specific Heat } \\
\text { Capacity } \\
\text { [J/(kg.K)] }\end{array}$ & $\begin{array}{c}\text { True } \boldsymbol{C C C}_{\text {surf }} \\
{[\mathbf{W} / \mathbf{K}]}\end{array}$ \\
\hline $\begin{array}{c}\text { Duralumin [42] } \\
\text { Pure Aluminium }\end{array}$ & 2770 & 177 & 875 & 4.1 \\
$\quad$ [31,42] & 2700 & 238 & 903 & 5.2 \\
Aluminium & 2700 & 238 & 903 & 1.45 \\
laminated film & & & & \\
(0.112 mm) [31] & & & & \\
$\begin{array}{c}\text { Steel (1\% C) [42] } \\
\text { Aluminium Alloy }\end{array}$ & 7801 & 43 & 473 & 1.24 \\
(existing design) & 2700 & 77 & 910 & 2.14 \\
\hline
\end{tabular}

\section{Cell thickness Analysis}

Fig.14 (b) and (c) demonstrate the relationship between cell thickness with cell energy density and cell $C C C_{\text {surf. }}$ In Fig.14(b), it is shown that, with reduced thickness, the cell energy density decrease is close to being linear. This is due to the increasing surface area to volume 
ration; the prismatic surface area (i.e. the can material) which takes a larger proportion of the cell mass at low thicknesses. By contrast, the decreased cell thickness delivers enhanced $C C C_{\text {surf }}$ values, due to the reduced number of layers of battery jellyroll, and therefore less temperature gradient across the cell thickness. In Fig.14(c), the relationship between cell energy density and $C C C_{\text {surf }}$, normalised against capacity, is shown. There is an exponential decay in the normalised against capacity $C C C_{\text {surf }}$ versus cell energy density, showing that the trend towards thicker cells to achieve higher energy density comes at the cost of large internal thermal gradients. This is not necessarily beneficial for OEMs nor the end users. Where is the optimum, is not known. The optimum will be a complicated function of cell design, how the cell is to be used, and thermal management system design. Hence, the development of a modelling tool capable of exploring these variables in this paper, and the introduction of the CCC to be considered alongside energy density on the cell datasheet.

For example, if the cell thickness is decreased from $36.5 \mathrm{~mm}$ to $18.36 \mathrm{~mm}$, then the $C C C_{\text {surf }}$ can be increased by $47 \%$ but at the cost of a $37 \%$ reduction in energy density. This may result in an increase in the pack level energy density if a more space and mass efficient thermal management system can be used. A detailed further experimental study on the various form factors of the cell could enhance and validate the above analysis, as a future work.

\section{Conclusion}

The study uses the revolutionary cell cooling coefficient (CCC) as an evaluation tool, together with a 3D thermally coupled discretised ECM, to deliver quantitative insights into lithium ion battery design and interactions with thermal management systems.

The developed model is able to simulate the voltage and thermal responses for a given cell well. The RMSE of the voltage responses for drive cycle noisy load and constant current square wave load are $8 \mathrm{mV}$ and $2.6 \mathrm{mV}$ respectively. The thermal prediction for the noisy load across the entire cell surface and cell thickness is within $0.99{ }^{\circ} \mathrm{C}$ and $0.4^{\circ} \mathrm{C}$ respectively. When simulating the surface Cell Cooling Coefficient, the RMSE for the thermal gradient across the cell thickness is below $0.09^{\circ} \mathrm{C}$ and the RMSE for the empirically derived true $C C C_{\text {surf }}$ is $0.14 \mathrm{~W} / \mathrm{K}$, and $C C C_{\text {surf }}$ values of 2.04 and $2.18 \mathrm{~W} / \mathrm{K}$ were measured 
experimentally and simulated respectively.

The CCC, as a cell evaluation metric, is used as a thermal parameterisation tool within the developed model. This single parameter delivers information on how well the cell is designed for thermal management, by quantifying the thermal gradient required across the thickness of the target cell, through the cell surface.

Here, for the first time, we conclude and quantify the relationship between the cell energy density and the ease of implementation for the thermal management system, through varying the cell thickness. By decreasing the cell thickness from $36.5 \mathrm{~mm}$ to $18.36 \mathrm{~mm}$, an enhancement of $47 \%$ of the $C C C_{\text {surf }}$ is achieved, but at the cost of a $37 \%$ decrease in cell energy density. However, changing the casing material from aluminium alloy into aluminium with the same casing thickness would increase the CCC by $143 \%$, with negligible impact on energy density (e.g. less than $0.1 \%$ ).

\section{Acknowledgement}

The authors would like to acknowledge the funding support received from Envision-AESC, Ltd. for Xiao Hua and funding from the Faraday Institution (faraday.ac.uk; EP/S003053/1), grant number FIRG003 for Gregory Offer. The work was also supported by Alessandro Picarelli from Claytex UK, Danny Montgomery from Thermal Hazard Technology UK and Yan Zhao from Imperial College London. 


\section{References}

[1] IEA, IEA(2019),World Energy Outlook 2019, Paris, n.d. https://doi.org/https://www.iea.org/reports/world-energy-outlook-2019.

[2] IEA, Global EV outlook 2018, Int. Energy Agency. (2018).

[3] C. Mckerracher, Electric Vehicle Outlook 2019, (2019).

[4] Y. Zhao, Y. Patel, T. Zhang, G.J. Offer, Modeling the Effects of Thermal Gradients Induced by Tab and Surface Cooling on Lithium Ion Cell Performance, J. Electrochem. Soc. 165 (2018) A3169-A3178. https://doi.org/10.1149/2.0901813jes.

[5] A. Hales, L.B. Diaz, M.W. Marzook, Y. Zhao, Y. Patel, G. Offer, The Cell Cooling Coefficient: A Standard to Define Heat Rejection from Lithium-Ion Batteries, J. Electrochem. Soc. 166 (2019) A2383-A2395. https://doi.org/10.1149/2.0191912jes.

[6] B. Wu, V. Yu, M. Marinescu, G.J. Offer, R.F. Martinez-botas, N.P. Brandon, Coupled thermal e electrochemical modelling of uneven heat generation in lithium-ion battery packs, 243 (2013) 544-554. https://doi.org/https://doi.org/10.1016/j.jpowsour.2013.05.164.

[7] X. Feng, X. He, M. Ouyang, L. Lu, P. Wu, C. Kulp, S. Prasser, Thermal runaway propagation model for designing a safer battery pack with $25 \mathrm{Ah} \mathrm{LiNi}$ x Co y Mn z O 2 large format lithium ion battery, Appl. Energy. 154 (2015) 74-91. https://doi.org/10.1016/j.apenergy.2015.04.118.

[8] T. Waldmann, M. Wilka, M. Kasper, M. Fleischhammer, M. Wohlfahrt-Mehrens, Temperature dependent ageing mechanisms in Lithium-ion batteries - A Post-Mortem study, J. Power Sources. 262 (2014) 129-135. https://doi.org/10.1016/j.jpowsour.2014.03.112.

[9] P. Ramadass, B. Haran, R. White, B.N. Popov, Capacity fade of Sony 18650 cells cycled at elevated temperatures: Part II. Capacity fade analysis, J. Power Sources. 112 (2002) 614-620. https://doi.org/10.1016/S0378-7753(02)00473-1.

[10] T.G. Zavalis, M. Klett, M.H. Kjell, M. Behm, R.W. Lindström, G. Lindbergh, Electrochimica Acta Aging in lithium-ion batteries : Model and experimental investigation of harvested LiFePO 4 and mesocarbon microbead graphite electrodes, 
Electrochim. Acta. 110 (2013) 335-348.

https://doi.org/10.1016/j.electacta.2013.05.081.

[11] Y. Troxler, B. Wu, M. Marinescu, V. Yufit, Y. Patel, A.J. Marquis, N.P. Brandon, G.J. Offer, The effect of thermal gradients on the performance of lithium-ion batteries, J. Power Sources. 247 (2014) 1018-1025.

https://doi.org/10.1016/j.jpowsour.2013.06.084.

[12] I.A. Hunt, Y. Zhao, Y. Patel, J. Offer, Surface Cooling Causes Accelerated Degradation Compared to Tab Cooling for Lithium-Ion Pouch Cells, J. Electrochem. Soc. 163 (2016) A1846-A1852. https://doi.org/10.1149/2.0361609jes.

[13] J. Xun, R. Liu, K. Jiao, Numerical and analytical modeling of lithium ion battery thermal behaviors with different cooling designs, J. Power Sources. 233 (2013) 47-61. https://doi.org/10.1016/j.jpowsour.2013.01.095.

[14] M.M. K.J. Kelly and M. Zolot, Battery Usage and Thermal Performance of the Toyota Prius and Honda Insight for Various Chassis Dynamometer Test Procedures, 17th Annu. Batter. Conf. Appl. Adv. (2001). https://www.nrel.gov/transportation/assets/pdfs/2002_batteryusage.pdf.

[15] A. Hales, M.W. Marzook, L. Bravo Diaz, Y. Patel, G. Offer, The Surface Cell Cooling Coefficient: A Standard to Define Heat Rejection from Lithium Ion Battery Pouch Cells, J. Electrochem. Soc. 167 (2020) 020524. https://doi.org/10.1149/1945$7111 / \mathrm{ab} 6985$.

[16] G. Xia, L. Cao, G. Bi, A review on battery thermal management in electric vehicle application, J. Power Sources. (2017). https://doi.org/10.1016/j.jpowsour.2017.09.046.

[17] D. Chen, J. Jiang, G.-H. Kim, C. Yang, A. Pesaran, Comparison of different cooling methods for lithium ion battery cells, Appl. Therm. Eng. 94 (2016) 846-854. https://doi.org/10.1016/j.applthermaleng.2015.10.015.

[18] Y. Deng, C. Feng, J. E, H. Zhu, J. Chen, M. Wen, H. Yin, Effects of different coolants and cooling strategies on the cooling performance of the power lithium ion battery system: A review, Appl. Therm. Eng. 142 (2018) 10-29. https://doi.org/10.1016/j.applthermaleng.2018.06.043.

[19] Q. Wang, B. Jiang, B. Li, Y. Yan, A critical review of thermal management models 
and solutions of lithium-ion batteries for the development of pure electric vehicles, Renew. Sustain. Energy Rev. 64 (2016) 106-128.

https://doi.org/10.1016/j.rser.2016.05.033.

[20] L.W. Jin, P.S. Lee, X.X. Kong, Y. Fan, S.K. Chou, Ultra-thin minichannel LCP for EV battery thermal management, Appl. Energy. 113 (2014) 1786-1794. https://doi.org/10.1016/j.apenergy.2013.07.013.

[21] Y. Huo, Z. Rao, X. Liu, J. Zhao, Investigation of power battery thermal management by using mini-channel cold plate, Energy Convers. Manag. 89 (2015) 387-395. https://doi.org/10.1016/j.enconman.2014.10.015.

[22] Y. wei Pan, Y. Hua, S. Zhou, R. He, Y. Zhang, S. Yang, X. Liu, Y. Lian, X. Yan, B. $\mathrm{Wu}, \mathrm{A}$ computational multi-node electro-thermal model for large prismatic lithium-ion batteries, J. Power Sources. 459 (2020) 228070. https://doi.org/10.1016/j.jpowsour.2020.228070.

[23] M. Doyle, J. Newman, The use of mathematical modeling in the design of lithium/polymer battery systems, Electrochim. Acta. 40 (1995) 2191-2196. https://doi.org/10.1016/0013-4686(95)00162-8.

[24] U.S. Kim, C.B. Shin, C.S. Kim, Effect of electrode configuration on the thermal behavior of a lithium-polymer battery, J. Power Sources. 180 (2008) 909-916. https://doi.org/10.1016/j.jpowsour.2007.09.054.

[25] H. Gu, Mathematical Analysis of a Zn\NiOOH Cell, J. Electrochem. Soc. 130 (1983) 1459. https://doi.org/10.1149/1.2120009.

[26] X. Lai, W. Gao, Y. Zheng, M. Ouyang, J. Li, X. Han, L. Zhou, A comparative study of global optimization methods for parameter identification of different equivalent circuit models for Li-ion batteries, Electrochim. Acta. 295 (2019) 1057-1066. https://doi.org/10.1016/j.electacta.2018.11.134.

[27] C. Zhang, W. Allafi, Q. Dinh, P. Ascencio, J. Marco, Online estimation of battery equivalent circuit model parameters and state of charge using decoupled least squares technique, Energy. 142 (2018) 678-688.

[28] C. Zhang, K. Li, J. Deng, S. Song, Improved Realtime State-of-Charge Estimation of LiFePO4 Battery Based on a Novel Thermoelectric Model, IEEE Trans. Ind. Electron. 
64 (2017) 654-663. https://doi.org/10.1109/tie.2016.2610398.

[29] H. He, R. Xiong, H. Guo, S. Li, Comparison study on the battery models used for the energy management of batteries in electric vehicles, Energy Convers. Manag. 64 (2012) 113-121. https://doi.org/10.1016/j.enconman.2012.04.014.

[30] X. Hu, S. Li, H. Peng, A comparative study of equivalent circuit models for Li-ion batteries, J. Power Sources. 198 (2012) 359-367. https://doi.org/10.1016/j.jpowsour.2011.10.013.

[31] Y. Zhao, L.B. Diaz, Y. Patel, T. Zhang, G.J. Offer, How to Cool Lithium Ion Batteries: Optimising Cell Design using a Thermally Coupled Model, J. Electrochem. Soc. 166 (2019) A2849-A2859. https://doi.org/10.1149/2.0501913jes.

[32] N. Damay, C. Forgez, M.P. Bichat, G. Friedrich, Thermal modeling of large prismatic LiFePO4/graphite battery. Coupled thermal and heat generation models for characterization and simulation, J. Power Sources. 283 (2015) 37-45. https://doi.org/10.1016/j.jpowsour.2015.02.091.

[33] DYMOLA Systems Engineering Introduction, (n.d.). https://www.3ds.com/productsservices/catia/products/dymola/.

[34] The Modelica Association, (n.d.). https://www.modelica.org/.

[35] Industry Solitions - Modelica Libraries - Battery Library, (n.d.). https://www.3ds.com/products-services/catia/products/dymola/industry-solutions/.

[36] P. Taheri, M. Yazdanpour, M. Bahrami, Transient three-dimensional thermal model for batteries with thin electrodes, J. Power Sources. 243 (2013) 280-289. https://doi.org/10.1016/j.jpowsour.2013.05.175.

[37] P. Taheri, M. Bahrami, Temperature Rise in Prismatic Polymer Lithium-Ion Batteries: An Analytic Approach, SAE Int. J. Passeng. Cars - Electron. Electr. Syst. 5 (2012) 164-176. https://doi.org/10.4271/2012-01-0334.

[38] U.S. Kim, C.B. Shin, C.-S. Kim, Modeling for the scale-up of a lithium-ion polymer battery, J. Power Sources. 189 (2009) 841-846. https://doi.org/10.1016/j.jpowsour.2008.10.019.

[39] Contact@fmi-standard.org, Functional Mock-up Interface, (n.d.). https://fmistandard.org/ (accessed May 22, 2020). 
[40] S. T, GitHub:CATIA-Systems / FMPy, (2020). https://github.com/CATIASystems/FMPy (accessed May 22, 2020).

[41] T.S. Community, SciPy.org: scipy.optimize.differential_evolution, (2019). https://docs.scipy.org/doc/scipy/reference/generated/scipy.optimize.differential_evoluti on.html\#scipy.optimize.differential_evolution (accessed May 22, 2020).

[42] T. David, Galat, Arnaud, Material Thermal Properties Databasee,University of Central Florida (UCF), (n.d.).

https://ncfs.ucf.edu/burn_db/Thermal_Properties/material_thermal.html. 